\title{
Transorbital endoscopic approaches to the skull base: a systematic literature review and anatomical description
}

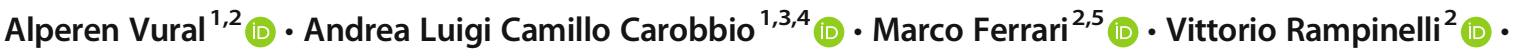 \\ Alberto Schreiber ${ }^{2}$ (D) Davide Mattavelli ${ }^{2}$ (D) $\cdot$ Francesco Doglietto $^{6}$ (D) Barbara Buffoli $^{7}$ (D) Luigi Fabrizio Rodella $^{7}$ (D) \\ Stefano Taboni ${ }^{2,5}$ (D) Michele Tomasoni $^{2}$ (D) - Tommaso Gualtieri ${ }^{2}$ (D) - Alberto Deganello ${ }^{2}$ (D) - Lena Hirtler $^{8}$ (D) \\ Piero Nicolai ${ }^{5}$ (D)
}

Received: 4 August 2020 / Revised: 9 December 2020 / Accepted: 29 December 2020 / Published online: 22 January 2021

(C) The Author(s) 2021, corrected publication 2021

\begin{abstract}
Transorbital endoscopic approaches are increasing in popularity as they provide corridors to reach various areas of the ventral skull base through the orbit. They can be used either alone or in combination with different approaches when dealing with the pathologies of the skull base. The objective of the current study is to evaluate the surgical anatomy of transorbital endoscopic approaches by cadaver dissections as well as providing objective clinical data on their actual employment and morbidity through a systematic review of the current literature. Four cadaveric specimens were dissected, and step-by-step dissection of each endoscopic transorbital approach was performed to identify the main anatomic landmarks and corridors. A systematic review with pooled analysis of the current literature from January 2000 to April 2020 was performed and the related studies were analyzed. Main anatomical landmarks are presented based on the anatomical study and systematic review of the literature. With emphasis on the specific transorbital approach used, indications, surgical technique, and complications are reviewed through the systematic review of 42 studies (19 in vivo and 23 anatomical dissections) including 193 patients. In conclusion, transorbital endoscopic approaches are promising and appear as feasible techniques for the surgical treatment of skull base lesions. Surgical anatomy of transorbital endoscopic approaches can be mastered through knowledge of a number of anatomical landmarks. Based on data available in the literature, transorbital endoscopic approaches represent an important complementary that should be included in the armamentarium of a skull base team.
\end{abstract}

Keywords Endoscopy, Neuroendoscopy, Transorbital, Orbit, Skull base

Alperen Vural and Andrea Luigi Camillo Carobbio equally share the first authorship.

Alberto Deganello, Lena Hirtler, and Piero Nicolai equally share the last authorship.

Alperen Vural

alperenvural@yahoo.com

1 Department of Otorhinolaryngology, Erciyes University Faculty of Medicine, 38039 Kayseri, Turkey

2 Unit of Otorhinolaryngology - Head and Neck Surgery, Department of Medical and Surgical Specialties, Radiological Sciences, and Public Health, University of Brescia, Piazzale Spedali Civili 1, 25123 Brescia, Italy

3 IRCCS Ospedale Policlinico San Martino, Genoa, Italy
4 Department of Surgical Sciences and Integrated Diagnostics (DISC), University of Genoa, Genoa, Italy

5 Section of Otorhinolaryngology - Head and Neck Surgery, Department of Neurosciences, University of Padua, Padua, Italy

6 Unit of Neurosurgery, Department of Medical and Surgical Specialties, Radiological Sciences, and Public Health, University of Brescia, Brescia, Italy

7 Section of Anatomy and Physiopathology, Department of Clinical and Experimental Sciences, University of Brescia, Brescia, Italy

8 Division of Anatomy, Center for Anatomy and Cell Biology, Medical University of Vienna, Vienna, Austria 


\section{Introduction}

Surgical approaches to the skull base (SB) significantly evolved over the last decades. Various meticulous anatomical studies have improved the understanding of SB anatomy from the endoscopic perspective, and transnasal endoscopic surgery has become the preferred approach for most pathologies of the median anterior SB and is being widely employed for a large number of lesions of the middle, posterior, and/or non-midline SB $[42,45,49,54,62]$. According to the contemporary literature, some tumors that were previously thought accessible only through open approaches are now being resected with a range of evolving novel techniques that exploit narrow anatomical corridors such as the sinonasal tract and orbit [47, 63].

Transnasal routes can be modified and combined depending upon the extent of the pathology, yet with the anatomical constraints posed by the course of relevant neurovascular structures $[30,62]$. Although modifiable and extremely versatile, transnasal endoscopic approaches might provide inadequate access to lesions with far lateral extension. In these circumstances, the orbit appears a reliable portal to overcome this limit [2]. Transorbital endoscopic approaches (TEA) have been surmised to provide a direct route to the lateral portion of the SB. Consequently, they have been adopted with increasing frequency to resect SB lesions over the last decade $[13,15,19,25,47,48,55,57]$.

While initially limited to the pathologies of the orbit, TEAs are now used either alone or in combination with transnasal approaches, allowing to resect a wide range of pathologies of the SB while avoiding more extended and potentially disfiguring transfacial/transcranial techniques [7]. The term "transorbital neuroendoscopic surgery" (TONES) describes a group of endoscopic surgical corridors that may be indicated for several lesions affecting the anterior and middle cranial fossae. Understanding the surgical anatomy of TONES requires a certain eclecticism, as it covers areas that are usually approached by different physicians through other routes, and needs anatomical landmarks to be identified from the endoscopic perspective. This is rewarded with limited morbidity, neither visible scars nor external craniotomies, and minimal brain retraction [47]. Consequently, potential damage to adjacent neurovascular structures is held to a minimum, patient recovery is rapid, and hospitalization short $[3,6,47,57]$. On the other hand, the enthusiasm raised by TEAs, which is witnessed by an increasing number of publications on this interesting topic, deserves to be weighted based on their genuine clinical indications and morbidity. This need contrasts with the fact that data on TEAs are heterogenous and fragmented throughout a number of single-institution publications.

The aim of the current study is to summarize the surgical anatomy of TEAs while providing objective clinical data on their actual employment and morbidity through a systematic review of the current literature.

\section{Materials and methods}

\section{Anatomical study}

Anatomical dissections were performed at the Laboratory of Endoscopic Anatomy of the University of Brescia (Brescia, Italy) and Division of Anatomy of the Medical University of Vienna (Vienna, Austria). Four fresh frozen cadaver heads were used. The specimens originated from voluntary body donations to the Division of Anatomy of the Medical University of Vienna (Vienna, Austria) $(n=3)$ or were provided by Medcure ${ }^{\circledR}$ (Portland, USA). Approval for the study by the local ethics commission was obtained (EC Nr. 1277/2016). Specimens were positioned supine, pinned, and fixed in a Mayfield head holder. Dissections were initiated with an external incision then continued endoscopically, following the surgical techniques described by Moe et al [47]. Endoscopic dissections were performed using a rigid 4-mmdiameter endoscope, $14 \mathrm{~cm}$ in length, with $0^{\circ}, 45^{\circ}$, and $70^{\circ}$ rod lenses. Images and videos were captured using a $4 \mathrm{~K}$ digital video system (Olympus ${ }^{\circledR}$, Japan). A high-speed drill was used for bone removal.

\section{Review protocol}

The study protocol was designed in accordance with the Preferred Reporting Items for Systematic Reviews and Meta-Analysis (PRISMA) statement. The database search included Pubmed (Medline) and Scopus. Key words searched were 'Transorbital' and 'Endoscopic Orbital'. Only Englishlanguage articles were included. Articles were screened and evaluated for eligibility excluding (1) case reports without anatomical studies; (2) transorbital procedures not including an endoscopic approach; (3) studies related to solely orbital pathologies; (4) letters to the editors, commentaries, reviews without cases or anatomical studies; and (5) other unrelated studies. The selected studies were included in the qualitative synthesis. The literature search was performed in April 2020 including only the studies published after 2000. Publications were reviewed based on title and abstract information to eliminate duplicate and irrelevant studies.

\section{RESULTS}

\section{Literature review}

The literature search with the keyword "Transorbital" revealed 435 records in Pubmed and 509 records in Scopus databases. Of those, 393 articles were duplicates. The search with the keyword "Endoscopic orbital" revealed 1502 records in Pubmed and 1631 records in Scopus of which 1208 were duplicates. After applying the exclusion criteria, a total of 42 
Fig. 1 Diagram showing selection process based on Preferred Reporting Items for Systematic Reviews and MetaAnalyses (PRISMA) for the studies related to endoscopic transorbital approaches
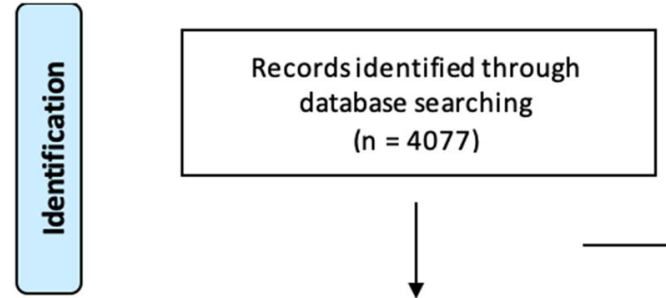

( $n=4077$ )
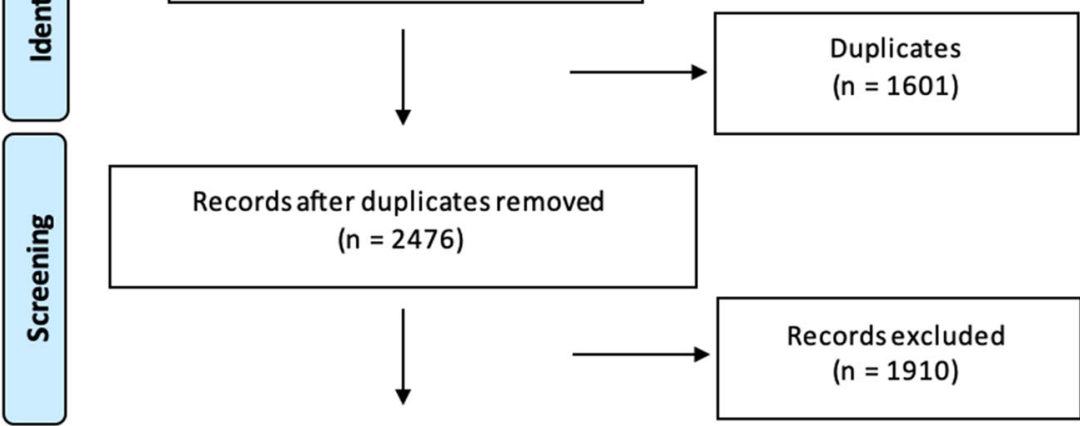

Records after duplicates removed

( $n=2476$ )
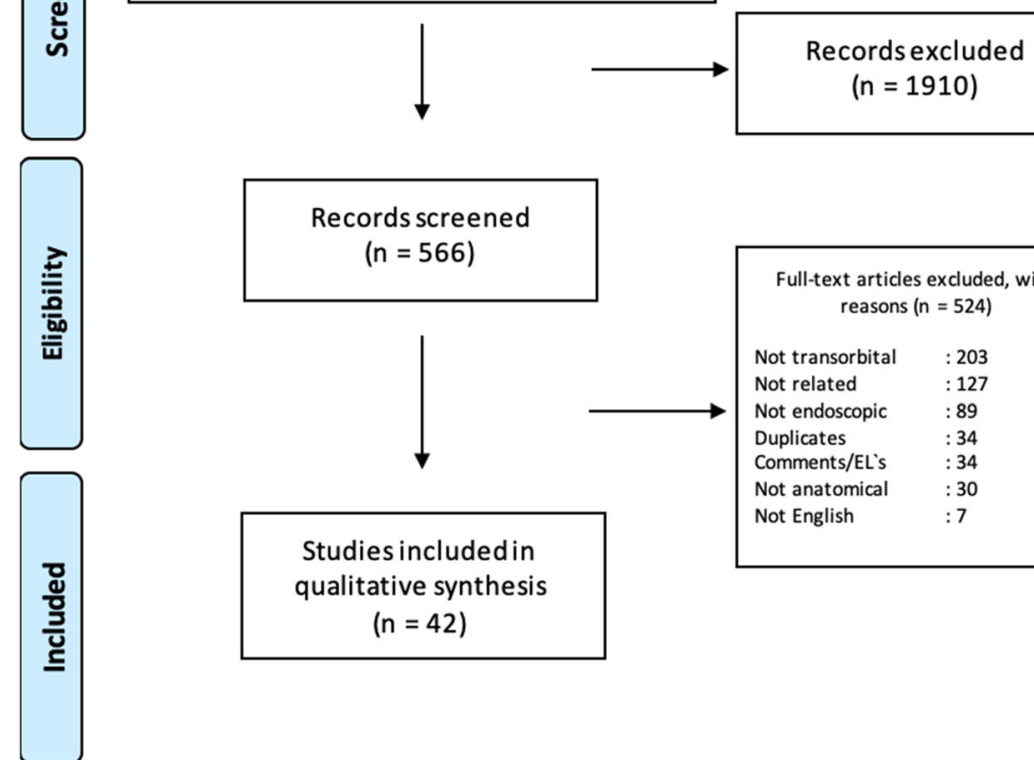

Studies includedin

qualitative synthesis

( $n=42$ )

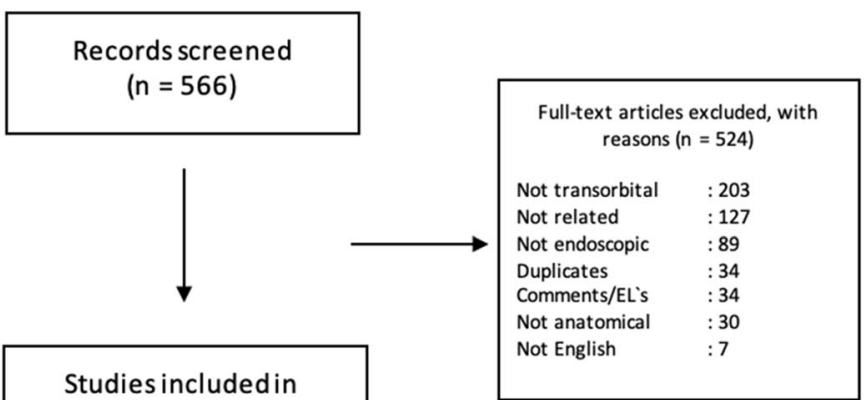

studies were included in qualitative synthesis. Figure 1 presents the PRISMA flowchart summarizing identification, screening, eligibility, and inclusion criteria. An increasing trend of publications over the last years was observed (Fig. 2). Table 1 presents the studies including living patients (or both case series/report and a cadaver study), whereas Table 2 summarizes purely anatomical studies.

\section{Indications}

TEAs refer to a group of surgical corridors that reach or pass through the orbit without removing any part of the bony orbital rim or adjacent structures [3, 46, 47]. These approaches may be indicated for the treatment of pathologies located within or adjacent to the orbit $[3,31,36,43,47]$. They may also be
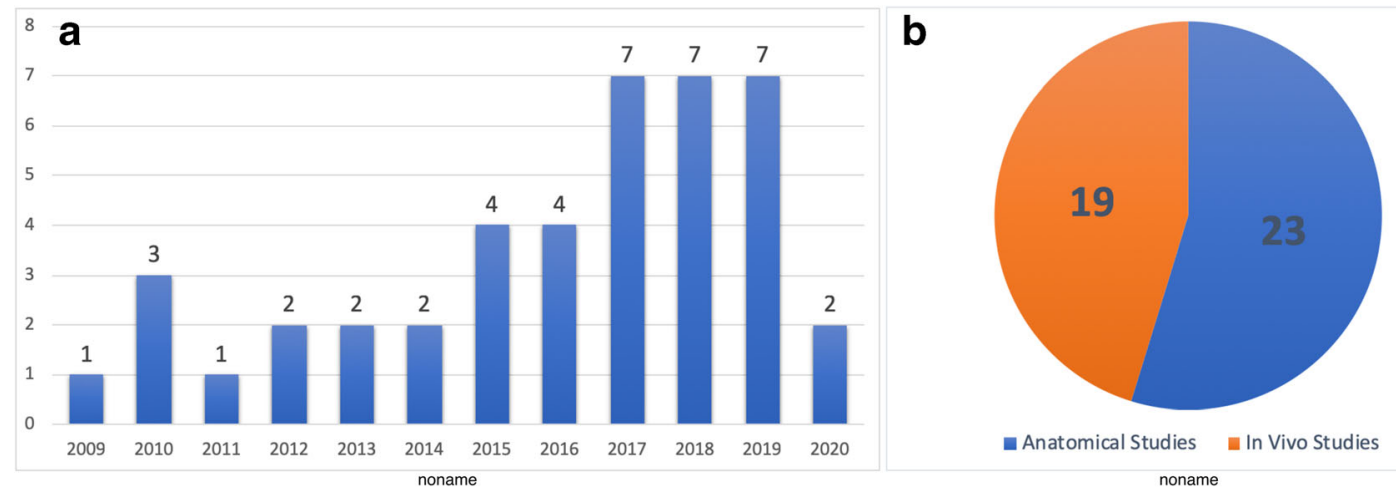

Fig. 2 A Chart graph showing the distribution of the number of the articles published throughout the years. B Pie graph showing the distribution of the papers according to study type 


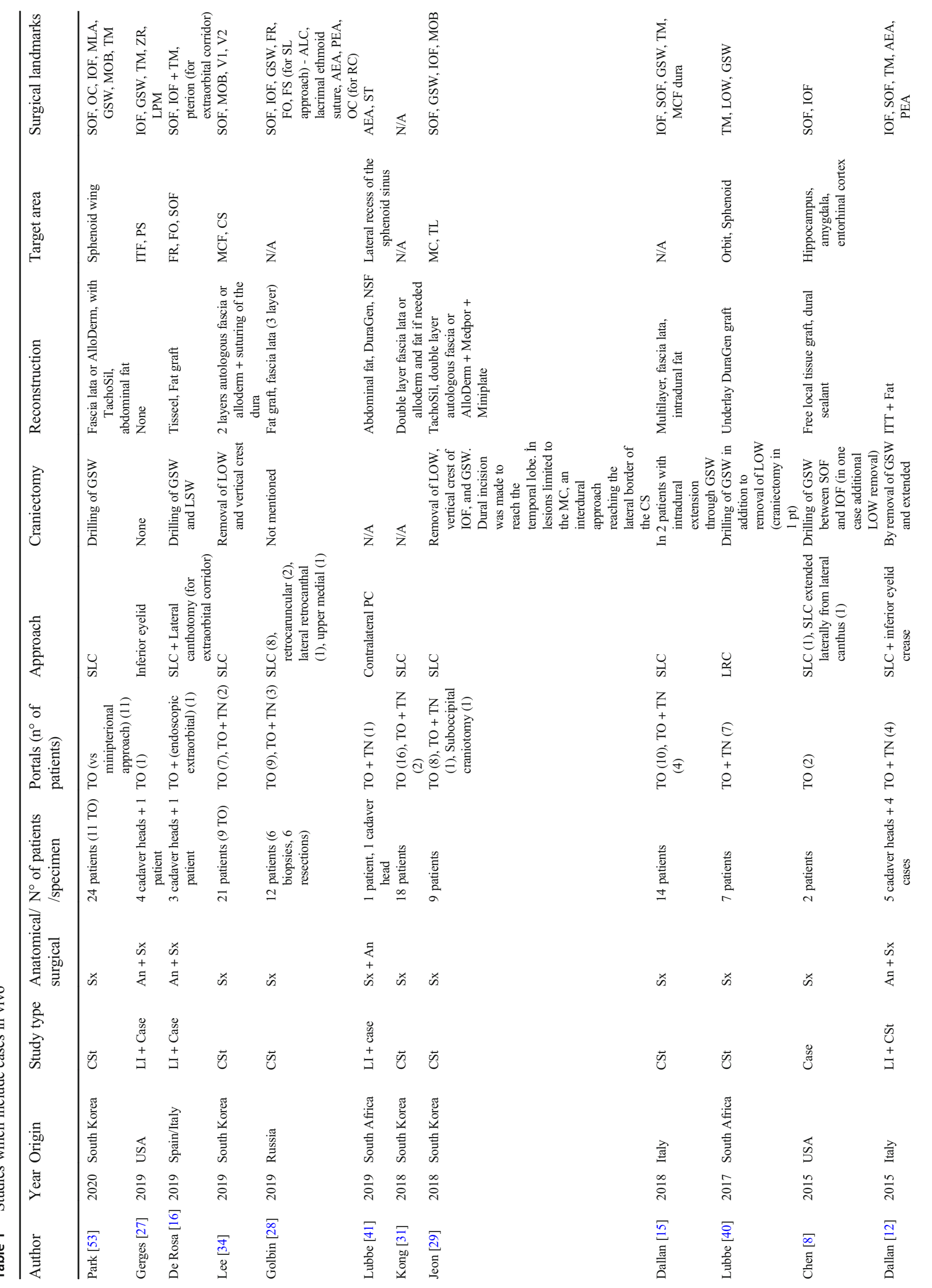




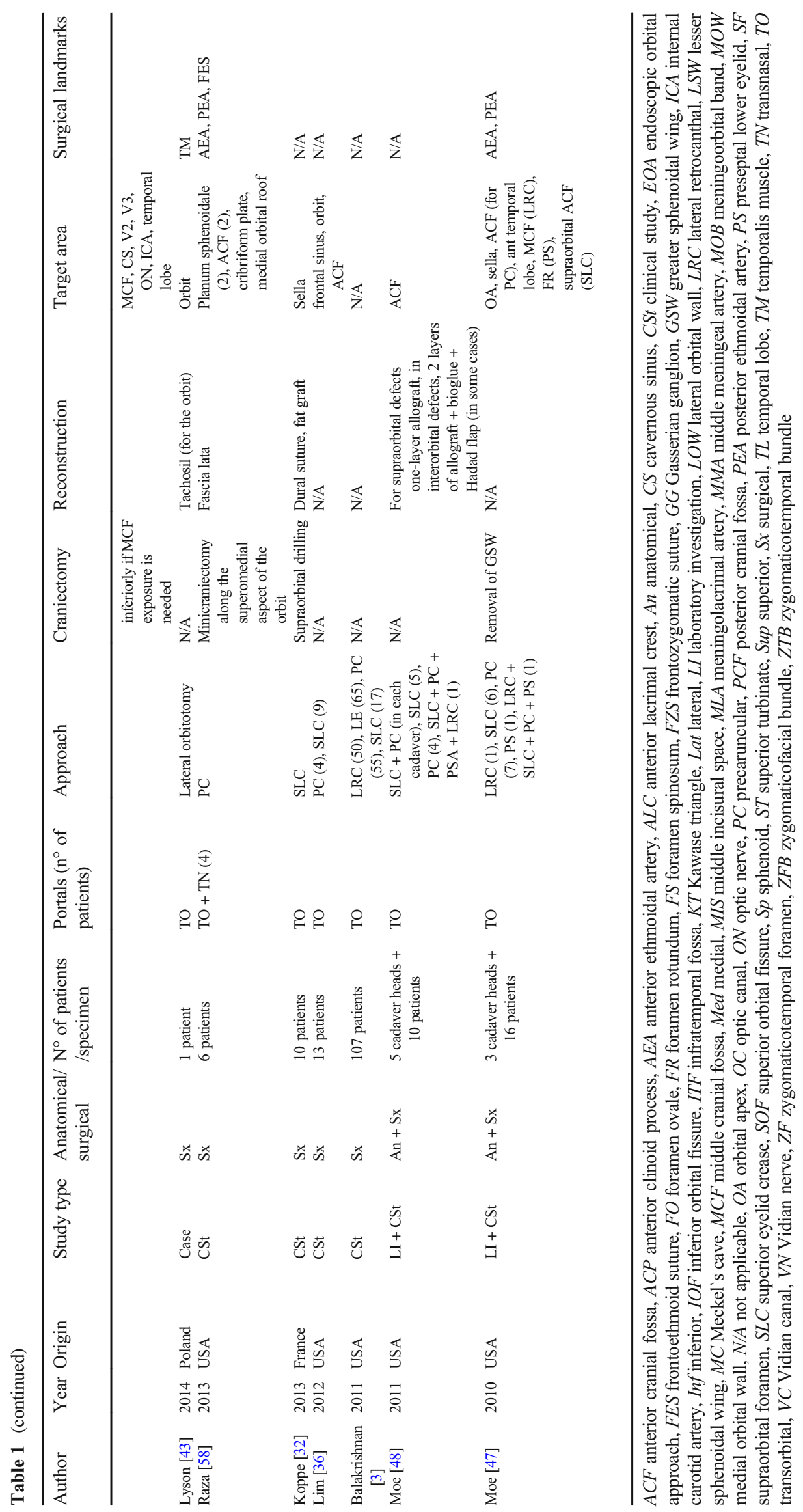




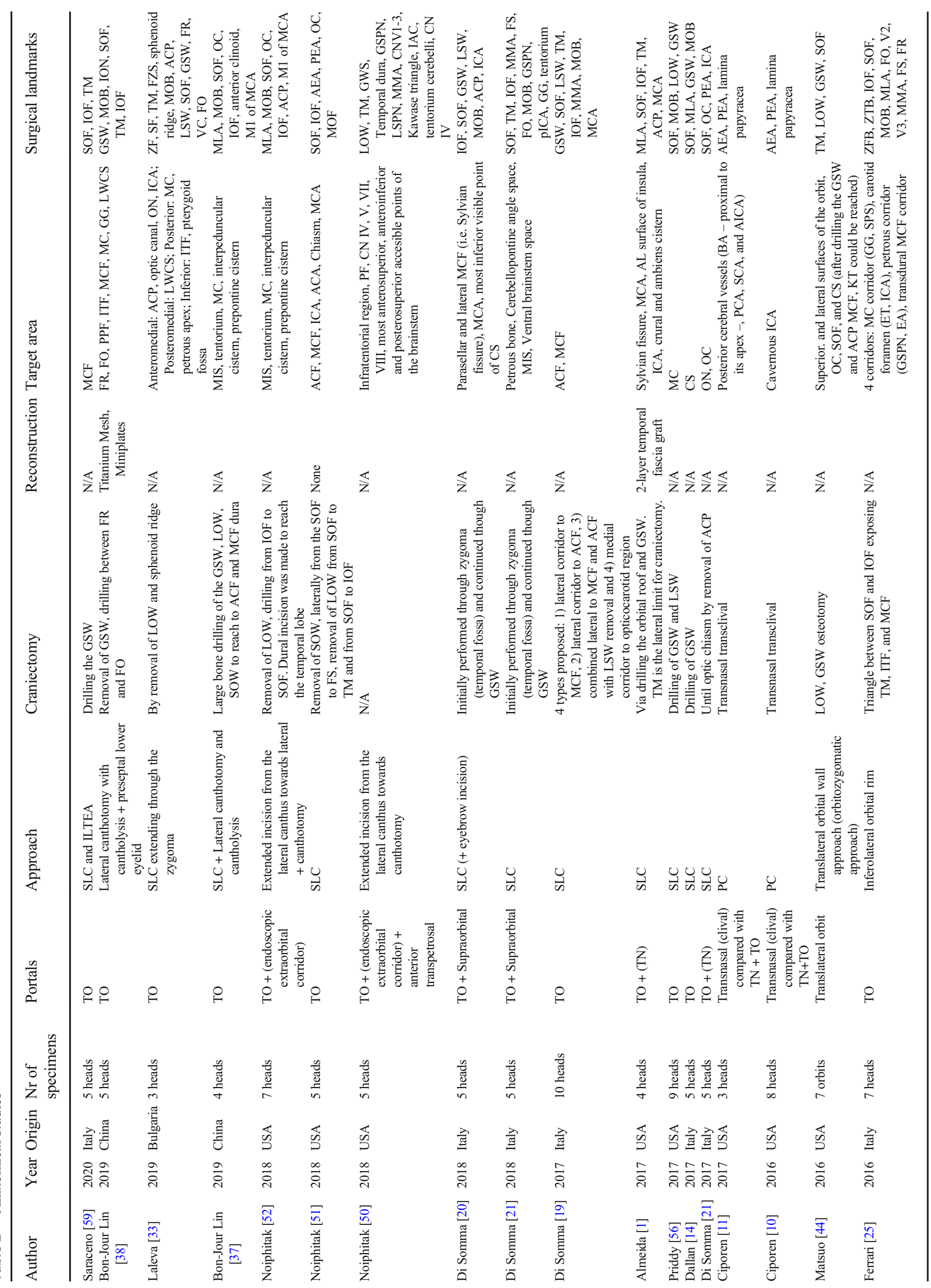




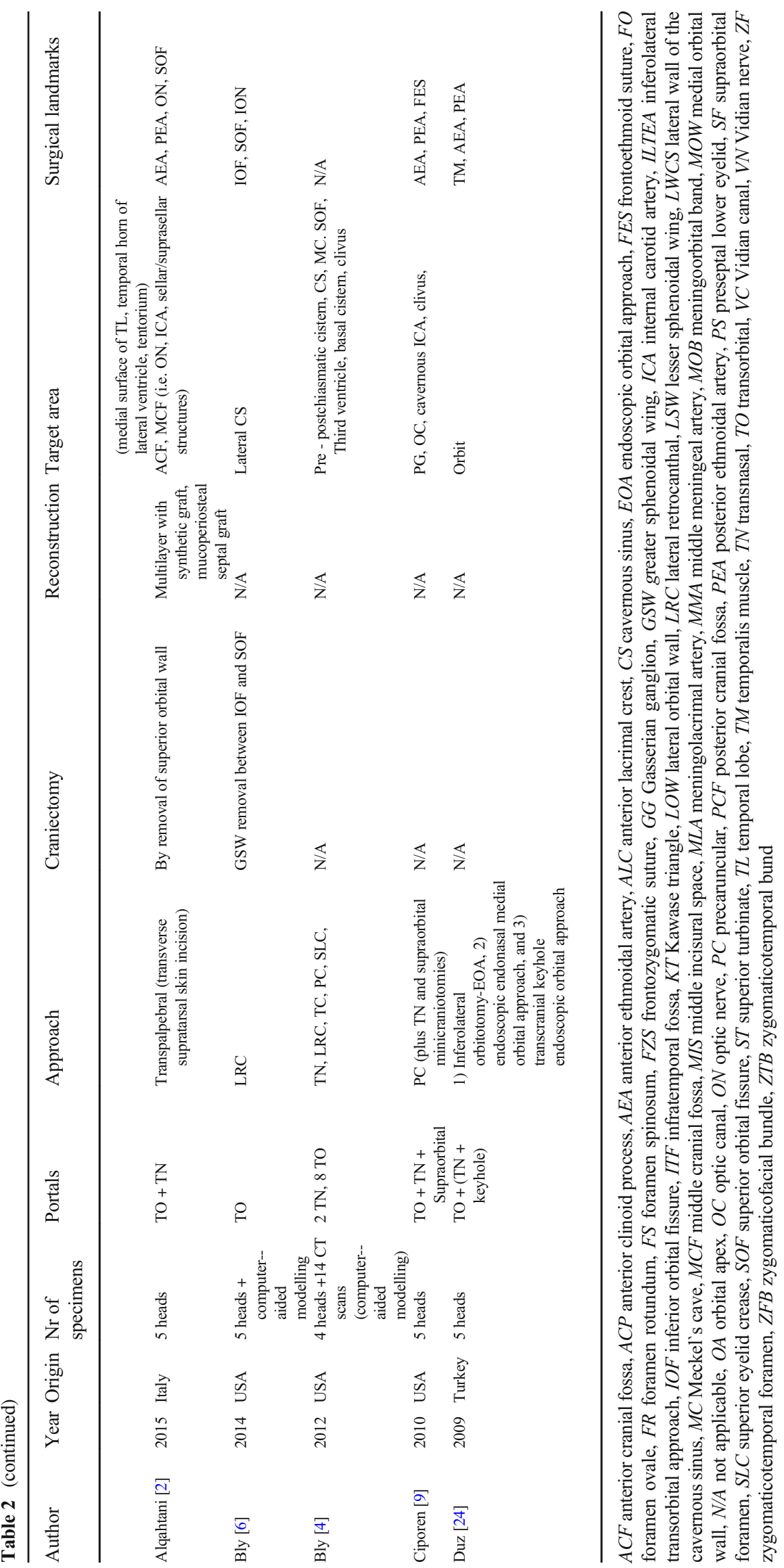


used to target distant anatomical regions by using the orbital cavity as a corridor $[1,2,4,5,8,10,14-16,18,19,21,25,27$, $29,31,33,34,37,38,40,41,47,48,56,57]$. They can be used either as a uniportal route $[3,5,8,14,18,27,33,36,38$, $47,48,50,56]$ or may be combined with transnasal, transmaxillary, or supraorbital paths $[1,2,4,9-12,16,18$, $20,24,28,29,31,34,41,44,46,50-52,58]$. The decision making regarding the approach must be done considering the critical (neurovascular) structures involved by or adjacent to the pathology, the space needed for insertion of instruments, capability to reach the target from the approach angle, possibility to perform a reconstruction, corridor-related morbidity, and experience of the surgical team. The patients' preference must also be taken into consideration $[3,8,11,14,16,18$, 25-27, 29, 34, 46, 50, 52, 56, 57].

\section{Surgical techniques}

Transorbital endoscopic surgery is based on 4 pillarapproaches through orbital quadrants: the superior eyelid crease (SLC), precaruncular (PC), the lateral retrocanthal (LRC), and the preseptal lower eyelid (PS), which cross the superior, medial, lateral, and inferior orbital quadrants, respectively (Figs. 3, 4, 5, 6, 7, 8, and 9) [47]. Several variants of

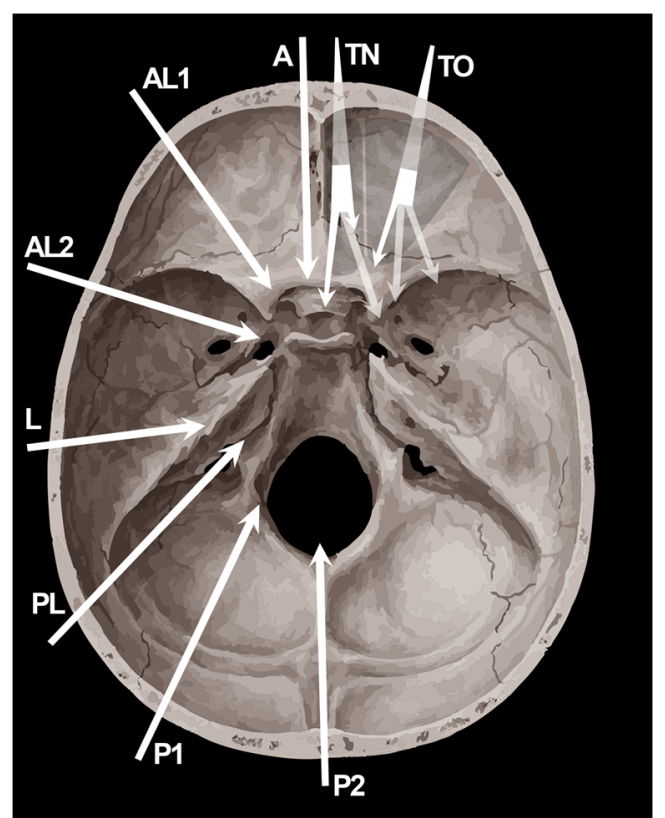

Fig. 3 Scheme depicting the extension and reach of transorbital endoscopic approaches (TO) with respect to transnasal endoscopic (TN) and most relevant open skull base approaches. A Anterior approaches (e.g., subfrontal); AL1, paramedian anterolateral approaches (e.g., supraorbital); AL2, anterolateral approaches (e.g., pterional, frontotemporal, orbito-zygomatic, frontotemporal-orbitozygomatic); L, lateral approaches (e.g., transpetrous, subtemporal middle cranial fossa, infratemporal); PL, posterolateral (e.g., trans-sigmoid, retrosigmoid); P1, paramedian posterolateral approaches (e.g., far lateral); P2, posterior approaches (e.g., suboccipital) [17] these pillar approaches have been described over the last decade in clinical and anatomical studies, each aiming to facilitate surgical goals [8, 9, 20, 24, 25, 29, 33, 44, 50-52, 59]. A thorough understanding of the anatomy of the eyelid is essential in each approach, and possible need for a reconstruction and additional corridors (i.e., multiportal approach) must also be precisely planned before surgery.

\section{Superior eyelid crease approach}

With the superior eyelid crease approach (Fig. 5), also named as upper eyelid approach, the superior orbit, frontal sinus,
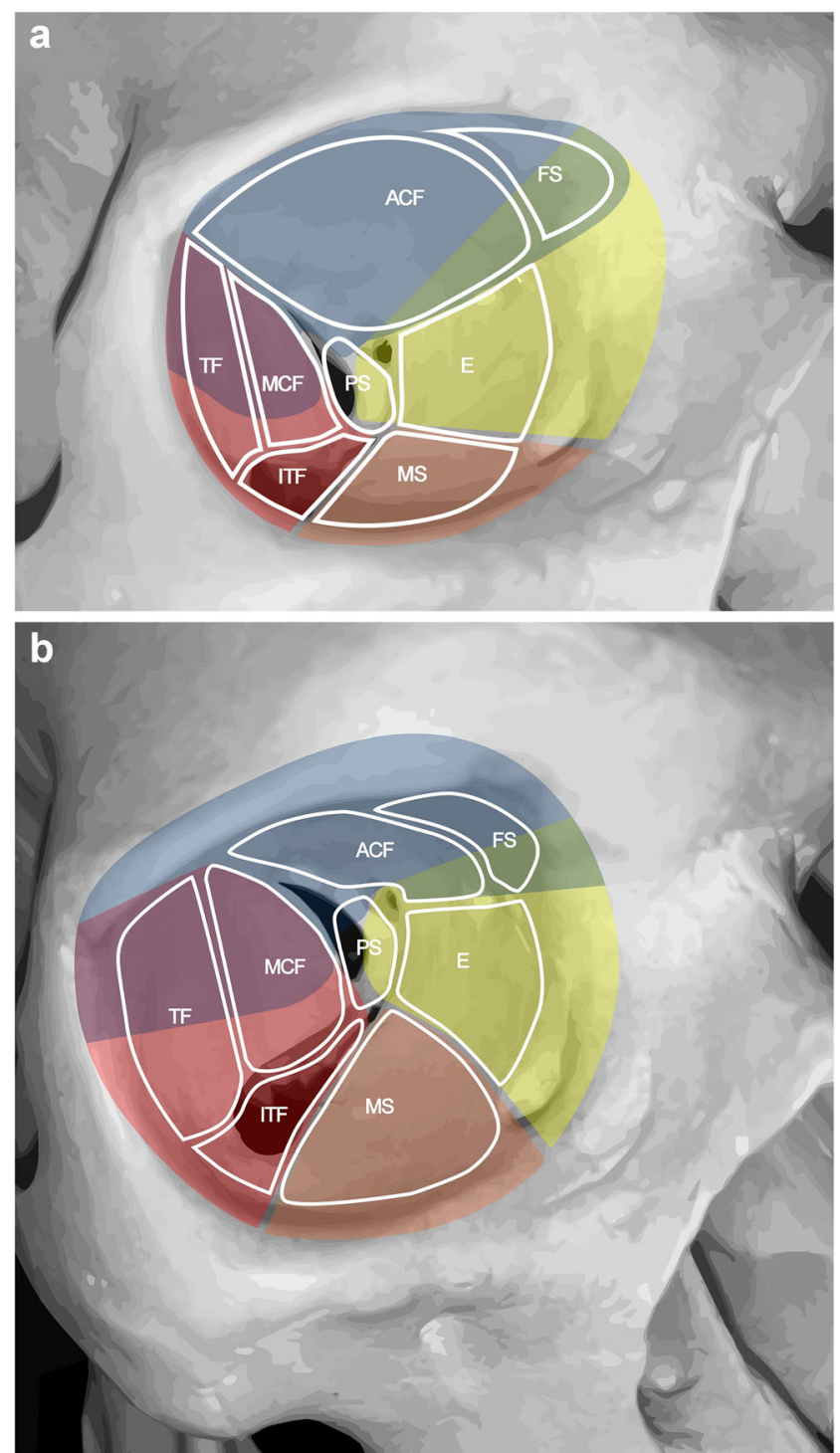

Fig. 4 A, B Schemas presenting the relations of transorbital approaches with different anatomical sites. Right orbit of a dry skull. ACF, anterior cranial fossa, E, ethmoids; FS, frontal sinus; ITF, infratemporal fossa; MCF, middle cranial fossa; MS, maxillary sinus; PS, TF, temporal fossa. The colors indicate the transorbital surgical approaches as blue, superior eyelid; yellow, precaruncular; red, lateral retrocanthal; orange, inferior eyelid 
Fig. 5 Superior eyelid and precaruncular approaches. A The superior eyelid crease approach starts with a skin incision performed at level of the supratarsal fold (black dashed line). B Superior tarsus (Ta) and levator palpebrae superioris muscle (LPSM) are identified. C The superior orbital rim is detached from the periorbit $(\mathrm{Pe})$. D The subperiosteal dissection is continued along the orbital roof (OR). The anterior (AEF), medialwhen present - (MEF), and posterior ethmoidal foramina (PEF) are identified in the medial aspect of the surgical corridor. The optic canal (OC) and the superior orbital fissure (SOF) are identified in the posterior portion of the orbit. E Both the precaruncular (PC) and lateral retrocanthal approach (LRC) display an overlap as regards the superior eyelid crease corridor. The trajectory of the precaruncular approach (white arrow, PC) lies at the medial aspect of the orbital cavity and requires sequential cut of the ethmoidal bundles. F The lateral retrocanthal approach (white arrow, LRC) is located in the lateral aspect of the orbital cavity and, similarly to the superior eyelid crease approach, offers direct exposure of the inferior orbital fissure (IOF), inferiorly, zygomatic bone (ZB) and greater sphenoidal wing $(\mathrm{GW})$ laterally, and SOF superiorly. AEA, anterior ethmoidal artery; Ost, optic strut

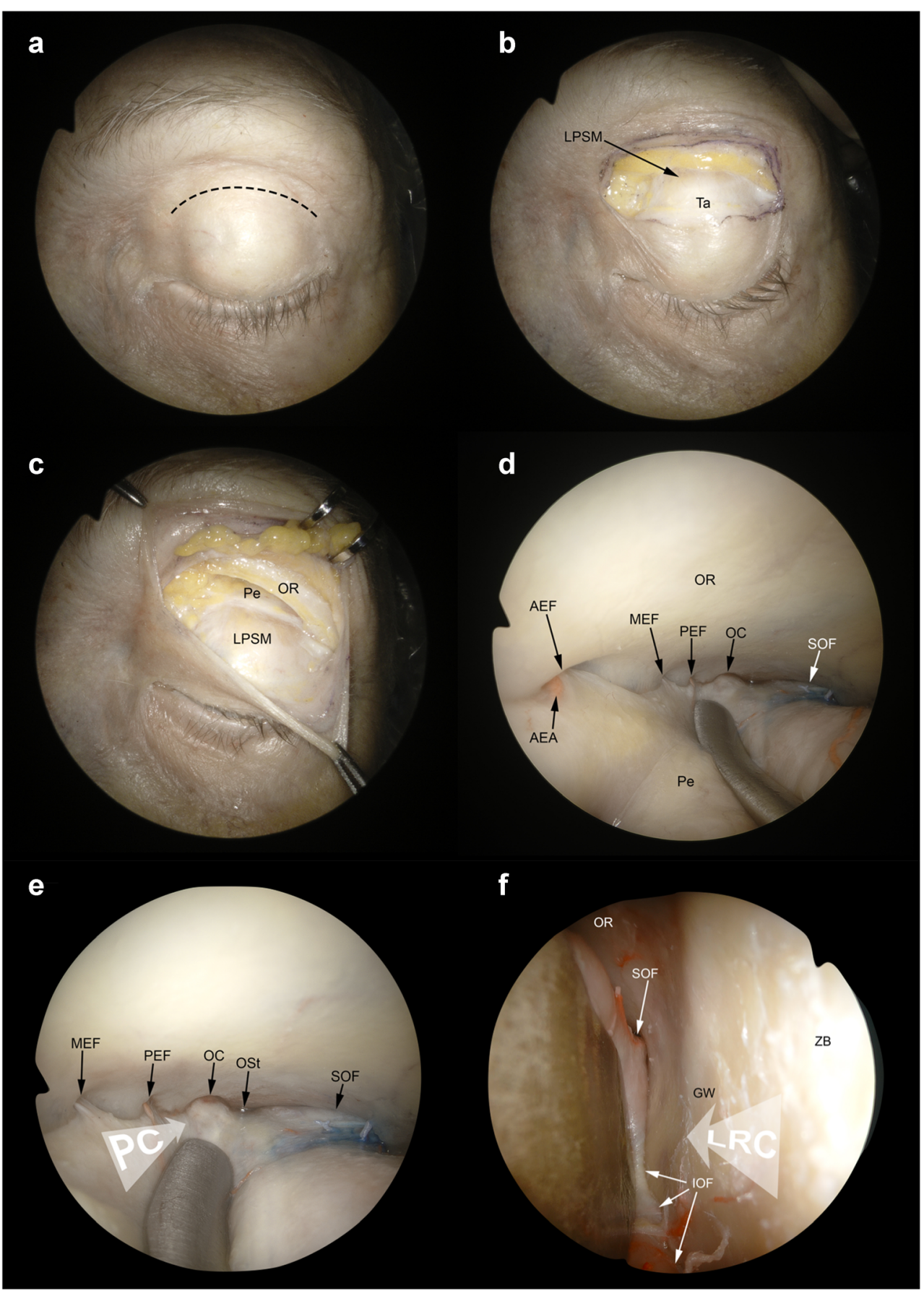

supraorbital and posterior-central portions of the anterior cranial fossa (ACF) and anterior skull base (ASB), and lateral portion of the middle cranial fossa (MCF) can be reached. This is the commonest approach used in transorbital endoscopic surgery $[2-4,8,12,15,16,18-21,28,29,31,32,34$, $36,38,47,48,51,53,56,59]$. The skin incision is made in the supratarsal fold as done in an upper blepharoplasty and can be tailored according to the path-to-target analysis [26, 47]. Deep to the preseptal orbicularis oculi muscle, the orbital septum is identified, through which the prelevator fat can be seen.
Dissection is continued raising the deep surface of the orbicularis muscle towards the superior orbital rim. This is crucial to avoid the aperture of the orbital septum and periorbit, which causes fat to prolapse into the surgical corridor. After the identification of the orbital rim, the periosteum is incised, and dissection is further progressed in a subperiosteal plane through the orbital roof. In the posterior portion of the orbit, the orbital end of the optic canal is identified, and medially the ethmoidal foramina can be visualized. According to the target, the dissection can be extended as far 


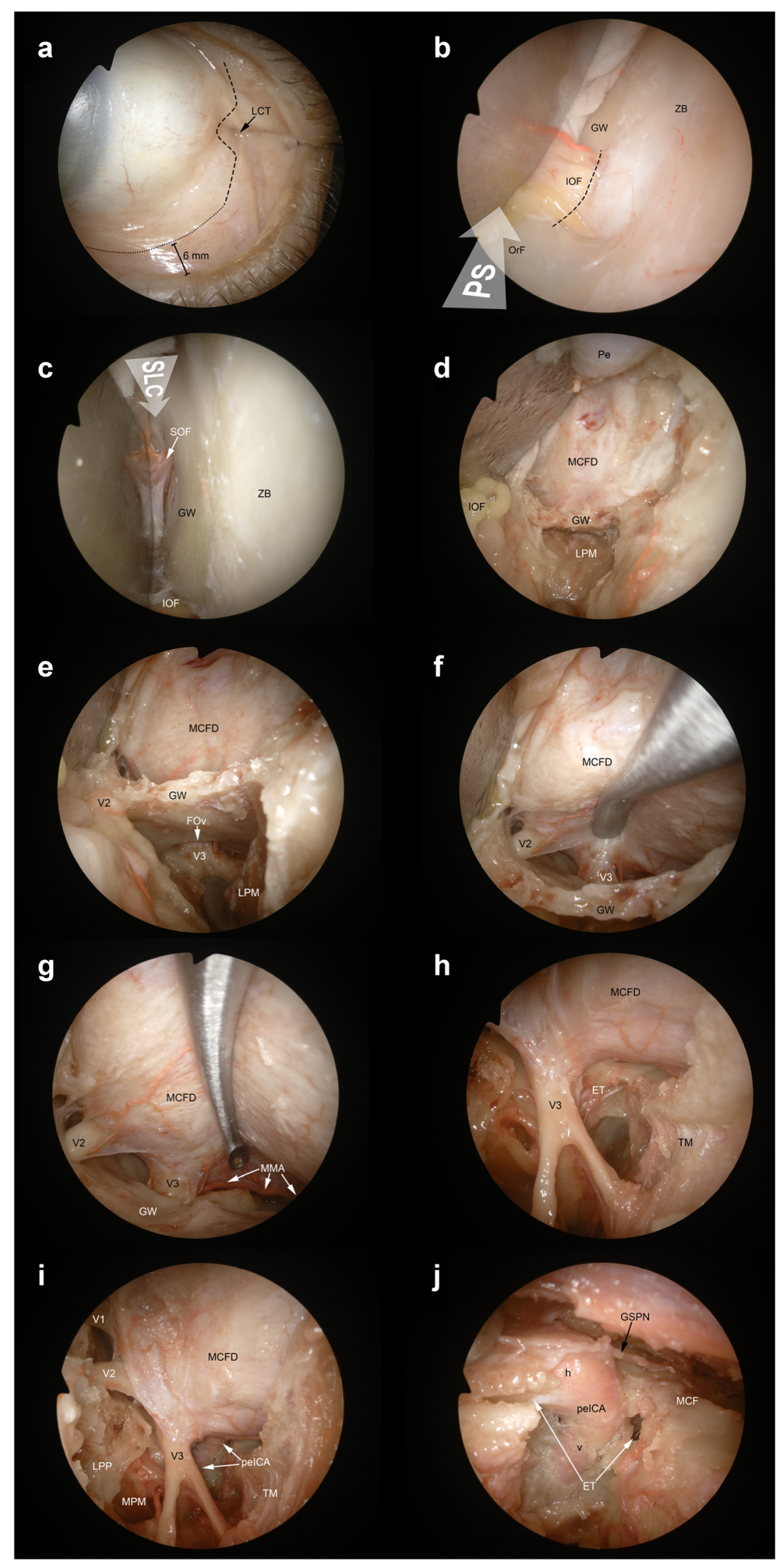


4 Fig. 6 Lateral retrocanthal and preseptal lower eyelid approaches. A The lateral retrocanthal (LRC) approach starts with a conjunctival incision (black dashed line) of the palpebral conjunctiva located on the lateral aspect of the orbital rim and passing posterior to the lateral canthal tendon (LCT). With the aim of increasing maneuverability and exposure through the inferolateral orbital quadrant, the lateral retrocanthal approach can be combined with a preseptal lower eyelid approach (PS), which is also started with a conjunctival incision (black dotted line) on the inner surface of the lower eyelid. B The preseptal lower eyelid approach (white arrow, PS) exposes the orbital floor (OrF) and early stops at the inferior orbital fissure (IOF), which needs to be cut (black dashed line) to extend exposure to the greater sphenoidal wing $(\mathrm{GW})$ while merging the inferior quadrant corridor with the lateral quadrant corridor (i.e. inferolateral transorbital endoscopic approach). C The lateral retrocanthal shares the potential to expose the greater sphenoidal wing and adjacent structures with the superior eyelid crease (SLC) approach (white arrow, SLC). D The removal of the coronal portion of the greater sphenoidal wing provides access to masticatory space, inferiorly, and middle cranial fossa dura (MCFD), superiorly. E The dissection can be continued along the extracranial aspect of the horizontal portion of greater sphenoidal wing by dissecting lateral pterygoid muscle (LPM) off the skull base. This maneuver provides exposure of the foramen ovale (FOv) and the extracranial tract of the mandibular nerve (V3) in the infratemporal fossa. F Epidural dissection along the anterior portion of the middle cranial fossa exposes the intracranial segments of maxillary (V2) and mandibular nerves. G Posterior and lateral to the mandibular nerve, the middle meningeal artery (MMA) runs from the foramen spinosum with a medial-to-lateral direction and provides vascular supply to the dura mater of this anatomical region. $\mathbf{H}$ After completing the removal of the bony contour of foramina ovale and spinosum and sectioning the middle meningeal artery, the bony-cartilaginous junction of the eustachian tube (ET) is identified. The eustachian tube crosses the mandibular nerve posteriorly and runs from superolateral to inferomedial. I The petrous segment of the internal carotid artery (peICA) is located posteriorly to the bony-cartilaginous junction of the eustachian tube. J After removing the eustachian tube and removing the anterior contour of the carotid canal, the vertical (v) and the horizontal (h) subtracts of the petrous portion of the internal carotid artery are visualized. GSPN, greater superficial petrosal nerve; LPM, lateral pterygoid muscle; LPP, lateral pterygoid plate; MPM, medial pterygoid muscle; $\mathrm{MCF}$, middle cranial fossa; $\mathrm{V} 1$, ophthalmic nerve; $\mathrm{Pe}$, periorbit; SOF, superior orbital fissure; TM, temporalis muscle; ZB, zygomatic bone

laterally as necessary. Identification of the superior orbital fissure (SOF) is paramount to achieve adequate orientation in the most posterior and lateral aspect of the corridor. If a more lateral corridor is needed, detachment of lateral canthal ligament can be done [26]. Diamond burr or a chisel is used to perform the craniectomy, which is sized and located depending on the targeted area $[16,37,56]$. The dura of the ACF and MCF can be elevated and/or incised based on the situation of the disease.

\section{Precaruncular approach}

This approach via the medial quadrant provides a direct and avascular access to medial orbital roof, lamina papyracea, ethmoidal arteries, cavernous sinus, parasellar and paraclinoid tracts of the internal carotid artery, optic nerve, and the central corridor towards the anterior skull base (ASB) $[3,4,9,10,26,36,46-48,58]$.

An incision between the caruncle and skin is made through the conjunctiva at the apex of the medial canthus. The avascular plane is entered deep to the Horner's muscle and to the posterior limb of the medial canthal tendon, and the periorbit is incised at crista lacrimalis (i.e., the posterior border of the lacrimal fossa). Dissection is performed from anterior to posterior between the periorbit and the medial orbital wall. The level of the ASB can be estimated by the ethmoidal bundles which are found along the fronto-ethmoidal suture and can be cauterized and cut. Reaching the posterior ethmoidal artery warns the surgeon that the optic nerve is close (i.e., around $7 \mathrm{~mm}$ posterior to the posterior ethmoidal foramen) and attention must be paid not to damage it (Fig. 5). After that level, dissection through the medial orbital wall makes the surgeon reach the orbital apex and then the bony removal is performed depending on the anatomical site of the target $[26,47]$.

\section{Lateral retrocanthal approach}

Via LRC approach, access to the deep lateral orbit, lateral aspect of the ACF, MCF, and infratemporal and temporal fossa is possible $[3,4,28,40,47]$. LRC overcomes morbidities like scarring and disruption of eyelid support caused by cutaneous or canthotomy incisions. A conjunctival incision is performed immediately posterior to the insertion of the lateral canthus (Fig. 6). The subperiosteal dissection is performed along the lateral orbital wall, from the inferior orbital fissure (IOF) to the orbital roof. This maneuver exposes the greater sphenoidal wing (GSW) (located below the SOF, above and lateral to the IOF, and posterior to the zygomatic bone), whose removal provides access to the temporal fossa, infratemporal fossa, and MCF [47]. The optic nerve is not at risk through this corridor as it stands medially in the orbit and is separated from the lateral wall by the contents of the SOF. At the superior aspect of the lateral orbital wall lies the sphenofrontal suture by which a superior craniectomy yields to lateral frontal fossa, while an inferior craniectomy guides to the MCF [47].

\section{Preseptal approach}

The PS approach is useful to access to the inferior orbit $[38,47]$. It can be combined with LRC or PC to increase maneuverability and exposure of the lateral and medial orbital quadrants, respectively (Fig. 6). It gives a 


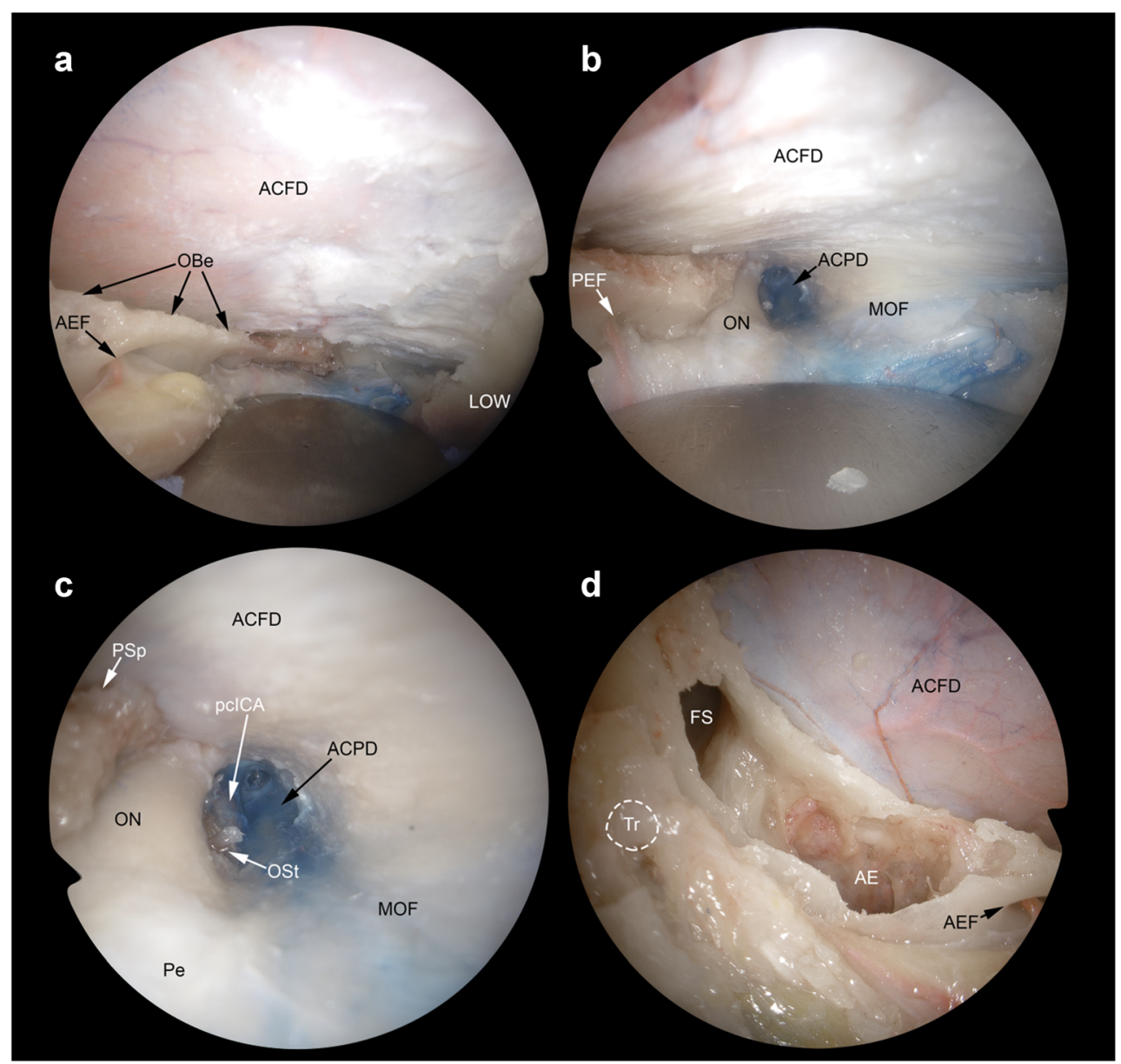

Fig. 7 Transorbital exposure of the lateral anterior skull base. A The removal of the orbital roof provides exposure of the anterior cranial fossa dura (ACFD), which can be resected or incised to expose the inferior aspect of the frontal lobe and related neurovascular structures. Among transorbital endoscopic approaches, superior eyelid crease and precaruncular provide the best exposure of this portion of the cranial base and adjacent structures. The orbital beak $(\mathrm{OBe})$ is the line located above ethmoidal foramina where the anterior cranial base turns from horizontal to cranially-convex (i.e., from the ethmoidal roof to the orbital roof, respectively). The lateral orbital wall (LOW) can be used as landmark to define the lateral limit of the craniectomy. B Posterior craniectomy can include the anterior clinoid process, medially, and lesser

path through orbital floor, maxillary sinus, IOF, and foramen rotundum. The conjunctival incision for a preseptal approach is made $2 \mathrm{~mm}$ inferior to the tarsus on the conjunctival surface of the lower eyelid $(6 \mathrm{~mm}$ inferior to the eyelid margin). The orbicularis oculi muscle is identified, and the dissection is carried out on its posterior face, which is anterior to the inferior orbital septum. The orbicularis muscle is followed through the inferior orbital rim, where the periosteum is incised and lifted off the orbital floor. Dissection may proceed further by sectioning the infraorbital bundle and IOF [47]. sphenoidal wing, laterally. This provides exposure of the intracanalicular portion of the optic nerve $(\mathrm{ON})$, anterior clinoid process dura (ACPD), and meningo-orbital fold (MOF), which is the area where the dura of anterior and middle cranial fossae turns into periorbit. C Focusing on the posteromedial portion of the surgical corridor, the optic strut (OSt) between the optic nerve and the paraclinoid tract of the internal carotid artery (pcICA). D In the most medial and anterior portion of the surgical corridor, bone removal of the superomedial orbital wall provide access to the frontal sinus (FS), frontoethmoidal region, and anterior ethmoid (AE). $\mathrm{AEF}$, anterior ethmoidal foramen; Pe, periorbit; PSp, planum sphenoidale; PEF, posteror ethmoidal foramen; Tr with white dashed line, position of the trochlea

\section{Extended and combined transorbital endoscopic approaches}

Along with the 4 pillar TEAs, extended or combined approaches can be applied in selected cases $[2,4,5,8-12,16$, $18,20,24,25,28,29,31,34,40,41,44,50-52]$. In the literature, TEAs are mostly used in combination with transnasal endoscopic procedures [1, 2, 4, 9-12, 22, 24, 28, $29,34,40,41]$. Other than transnasal corridors, different additional extraorbital corridors, such as supraorbital, lateral orbital, and pterional, have also been investigated and described in combination with transorbital routes (Figs. 7, 8, and 9) [9, $16,20,44,51,52]$. Transorbital extended approaches, in 
which more than one orbital quadrant was used, have also been presented $[25,59]$.

\section{Endoscopic transorbital craniectomy and bony landmarks}

The term craniectomy describes the removal of the bone cover on the dura with no bone repositiong at the end of the procedure [26]. The type of craniectomy is determined by the anatomo-surgical target for the underlying pathology. A drill, ultrasonic dissector, or chisel can be used to remove the bone at the desired site [47]. Surgeon should be familiar with the bony landmarks when performing a craniectomy. The thickness of bone varies throughout the orbital walls and different landmarks need to be exposed to complete the bone removal safely and accurately. In the 33 studies in which the craniectomy was mentioned in the text, SOF was the most common landmark $(75.8 \%)$, followed by the IOF $(54.5 \%)$ and GSW (39.3\%). The other anatomical structures that were pointed as landmarks were temporalis muscle (TM), lateral orbital wall (LOW), medial orbital wall (MOW), anterior ethmoidal artery (AEA), posterior ethmoidal artery (PEA), lesser sphenoidal wing (LSW), meningo-orbital band (MOB), frontozygomatic suture (FZS), anterior clinoid process $(\mathrm{ACP})$, optic nerve $(\mathrm{ON})$, optic canal $(\mathrm{OC})$, internal carotid artery (ICA), foramen ovale (FO), foramen rotundum (FR), foramen spinosum (FS), vidian canal (VC), vidian nerve $(\mathrm{VN})$, zygomaticotemporal foramen (ZF), supraorbital foramen (SF), frontoethmoidal suture (FES), zygomaticofacial bundle (ZFB), zygomaticotemporal bundle (ZTB), orbital apex (OA), anterior lacrimal crest (ALC), and meningolacrimal artery (MLA) $[1,2,4,5,8-16,18-20,24$, $25,27-29,32-34,37,38,40,41,44,47,51-53,56,58]$.

\section{Reconstruction}

As in general in SB surgery, reconstruction may be necessary to achieve a safe separation between different compartments (i.e., sinonasal tract, orbit, intracranial space). Postoperative cerebrospinal fluid (CSF) leak is a common concern related to TEAs and the surgeon must be familiar with different reconstructive techniques. In case of small defects with limited CSF leak, reconstruction is deemed unnecessary thanks to the support of the orbital structures $[1,14,56]$. For larger defects, reconstruction is indeed required, and the technique of reconstruction has to be tailored according to pathology, type of approach, and craniectomy size and site. When the defect is extended beyond the limits of the orbit (e.g., frontal sinus, cribriform plate, planum sphenoidale, lateral recess of the sphenoid), watertight closure should be achieved following the principles of transnasal endoscopic SB reconstruction [3, $41,47,48,58]$. Various materials such as autologous grafts (e.g., fascia lata, temporalis fascia, iliotibial tract, abdominal fat, septal mucoperichondrium) or synthetic materials (e.g., TachoSil ${ }^{\circledR}$, AlloDerm ${ }^{\circledR}$, DuraGen $\left.{ }^{\circledR}\right)$ have been used either alone or in combination $[8,12,14,16,28,29,31,32,34,38$, $40,41,43,48,53,58]$. In the majority of the studies, a multilayer reconstruction was conducted. A total of 74 patients required dural reconstruction, and postoperative CSF leak was reported in $3(4.1 \%)[8,12,15,16,28,29,31,32,34$, $40,41,48,53,58]$. Even after the reconstruction of large defects, the risk of CSF leak appears to be low as the orbital contents keep the reconstruction in place and tight $[1,12,14$, $46,48,56]$. Pulsation of the globe may be noted for 1 to 2 weeks postoperatively, which generally resolves spontaneously $[8,56,60]$. In addition, in order to prevent postoperative enophthalmos, Medpor can be placed over the dural defect as a buttress [29]. When the lateral orbital rim was removed in extended TOA, the orbital rim can be reconstructed by a mini plate or a titanium mesh $[29,38]$.

\section{Complications}

TEAs provide the chance to avoid some complications related to open craniotomies. However, by nature, they also have risks of complications. A total of 60 complications were reported in 193 cases presented (Tables 3 and 4) $[3,8,12,15$, $16,28,29,31,34,53,58]$. The majority of the complications reported were transient. Balakrishnan et al. [3] reported 3 persistent vision loss after surgery (3\% of cases), Golbin et al. [28] reported one persistent abducens nerve paresis, and Lee et al. [34] reported postoperative facial numbness in $38.1 \%$ of their patients which did not resolve. When the complications were evaluated in terms of Clavien-Dindo classification, all except one were Grade 1 and 2 [23]. The only complication requiring surgical intervention (Grade $3 b$ ) was an orbital pseudomeningocele which resolved after shunt insertion [8]. Table 5 shows the Clavien-Dindo classification for grading complications [23].

\section{Discussion}

TEAs, initially described as ancillary alternatives to traditional transcranial/transnasal routes, have been evolving to the state of well-established surgical methods, which are intended to overcome the limits of conventional procedures for selected pathologies of the $\mathrm{SB}$, either alone or in combination with other techniques [12, 39, 47]. For this reason, they raised a progressively increasing interest, as evident from the number of publications in a relatively short timeframe (Fig. 2). They have become relevant tools in SB surgery, facilitating access 

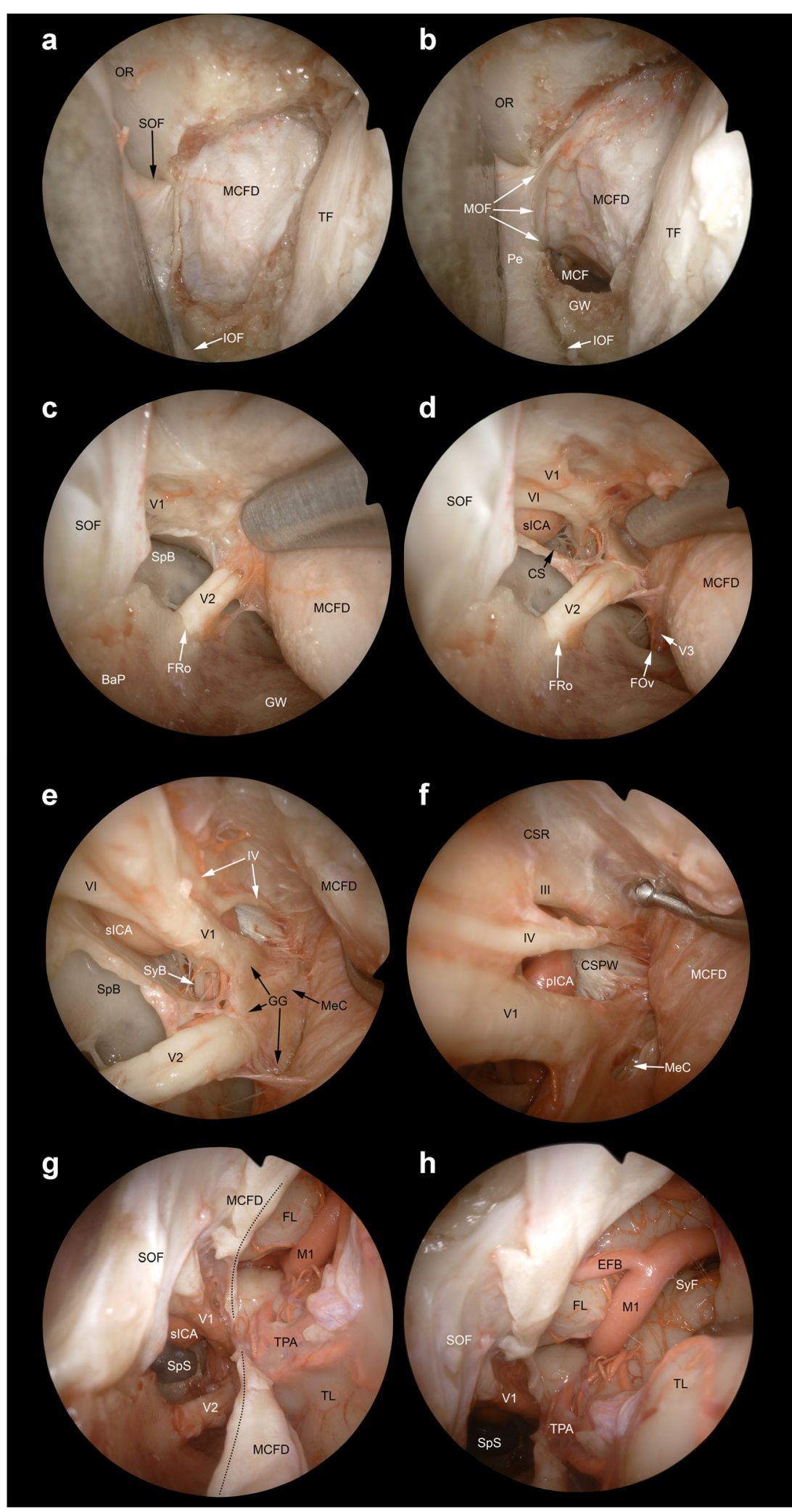

to a number of sites deemed challenging to reach, yet with relatively low morbidity [39, 41, 47].
In order to achieve the surgical goal, the surgical approach must be precisely selected, which majorly depends on the 
4 Fig. 8 Transorbital exposure of the lateral middle skull base, parasellar area, and Sylvian fissure. A The middle cranial fossa dura (MCFD) can be exposed through a craniectomy in the area between the superior orbital fissure (SOF) and inferior orbital fissure (IOF). This portion of the skull base can be exposed through both the superior eyelid crease approach and lateral retrocanthal approach. The former provides a slightly descending trajectory towards the middle cranial fossa $(\mathrm{MCF})$, whereas the latter route is parallel to the plane of the horizontal portion of the greater sphenoidal wing $(\mathrm{GW})$. B The meningo-orbital fold (MOF) is identified as the line where the dura of the middle and anterior cranial fosse merge with the periorbit. C Epidural dissection along the middle cranial fossa allows exposure of the oftalmic (V1) and the maxillary (V2) branches of the trigeminal nerve, which run towards the superior orbital fissure and foramen rotundum (FRo), respectively. D Interdural dissection above the trigeminal branches provides access to the parasellar area and allows identification of the mandibular branch of the trigeminal nerve (V3) and foramen ovale (FOv). The cavernous sinus (CS) is identified above the ophthalmic nerve (i.e., infratrochlear or Parkinson's triangle) and in the space between the ophthalmic and maxillary nerves (i.e., anteromedial or Mullan's triangle) and the parasellar tract of the internal carotid artery (sICA), abducens nerve (VI), and trochlear nerve (IV) are exposed. E Further posterior interdural dissection exposes the Gasserian ganglion (GG) and Meckel's cave (MeC). F The oculomotor nerve (III), cavernous sinus roof (CSR), posterior wall of the cavernous sinus (PWCS), and paraclival portion of the internal carotid artery ( $\mathrm{pICA}$ ) can be identified by further elevating the dura propria of the parasellar area. $\mathbf{G}$ The dura propria of the parasellar area and lateral middle cranial base is incised (black dotted line) to access the intradural compartment Sylvian fissure (SyF). H The first tract of the middle cerebral artery (M1), early frontal branch (EFB), and temporal polar arteries (TPA) are identified between the frontal (FL) and temporal lobe (TL). BaP, base of the pterygoid process; OR, orbital roof; Pe, periorbit; SyB, sympathetic branch of the abducens nerve; SpB, sphenoid body; TF, Temporal fossa

quadrant of the orbit that is involved by or is the most forthright route to the target pathology $[46,47]$. The basic requirement to safely harvest a transorbital surgical corridor and properly manipulate the lesion is sound knowledge of surgical anatomy. As learnt from transnasal endoscopic surgery, this should ground on the understanding of anatomical landmarks, which are basic anatomical relationships through which the surgeon can maintain orientation even in an intricate surgical corridor. The present paper systematically summarizes the main landmarks that were emphasized throughout available publications (Tables 1 and 2; Figs. 3, 4, 5, 6, 7, and 8). The created pathway through the target needs to give the surgeon optimal visualization and provide space for the use of endoscopic instrumentation. This is crucial both for the manipulation of the target and SB reconstruction. By TEAs, this short and direct path yielding to the needed comfortable working space can be frequently achieved, but one should keep in mind the spectrum of potential surgical alternatives to offer the best treatment to patients. The flexibility that the SB surgeon/team has in hand, which is the ability to extend or combine various approaches, provides a significant comfort and success in "complex" procedures [26, 39, 46, 47]. The surgeon can benefit from the possible better exposure provided by a combination of approaches. In a recent study, it was indicated that the endoscopic transnasal approach better exposes the inferomedial $1 / 3$ of the SOF and the cavernous sinus while the TEA yields a better exposure of the superolateral $2 / 3 \mathrm{~s}$ of the SOF. A combination of the two approaches can make it feasible to access the entire SOF endoscopically [35]. In another study, the combined transnasal-transorbital approach to the petrous apex was investigated in cadavers in order to quantify the amount of bone removal that can be obtained via each pathway, and the authors concluded that with a combined approach, 97\% of the bone removal can be performed [61].

The application of these procedures is best set by close collaboration between surgeons from different specialties such as otorhinolaryngology, neurosurgery, and ophthalmology. The SB surgeon can be unfamiliar with transorbital procedures. There doubtlessly exists a learning curve which can best be surpassed by proper anatomical training and teamwork $[2,39]$. The proper instrument setting is also important for performing this type of surgery which has to include an oculoplastic set with retractors, corneal protectors, lacrimal probes, a SB endoscopic set with high-quality endoscopes (0, 30, 45 and 70 degrees), drill, endoscopic Doppler probe. and surgical navigation system [46]. Dedicated instruments specifically designed for this type of surgery are worth designing and testing in order to overcome pitfalls like orbital fat blocking the view. The surgical team always needs to keep in mind that there may be need to intraoperatively shift the approach from endoscopic to an open one, and the preoperative planning must include every possible scenario on which the patient should be clearly informed and consented [26, 39].

The TEAs have been applied to various anatomical sites of the SB in several clinical studies. Orbital cavity and adjacent portions of the ASB and MSB are the most frequently targeted areas. Other potential targets have been recently analyzed and discussed. Gerges et al.[27] investigated the application of TEA for the ITF and PPS in anatomical specimens. They also presented a case with a recurrent glioblastoma of the ITF, which was approached through TEA for a biopsy. The authors conclude that TEA can be a safe alternative with less morbidity in this area, adding that pathologies extending inferiorly to the masticator space and neck may be a contraindication but those that extend to the MCF and spread anteriorly with orbital extension are more susceptible to this approach. Lee et al. [34] indicated that access to the CS via TEA may be considered more practical than the endoscopic transnasal approach. The reason of this provision is explained by the shorter access route, ability to perform interdural dissection through the CS, ability of facilitating exploration through the anteromedial (between V1 and V2) and anterolateral (between V2 and V3) corridors, and avoidance of morbidity caused by 

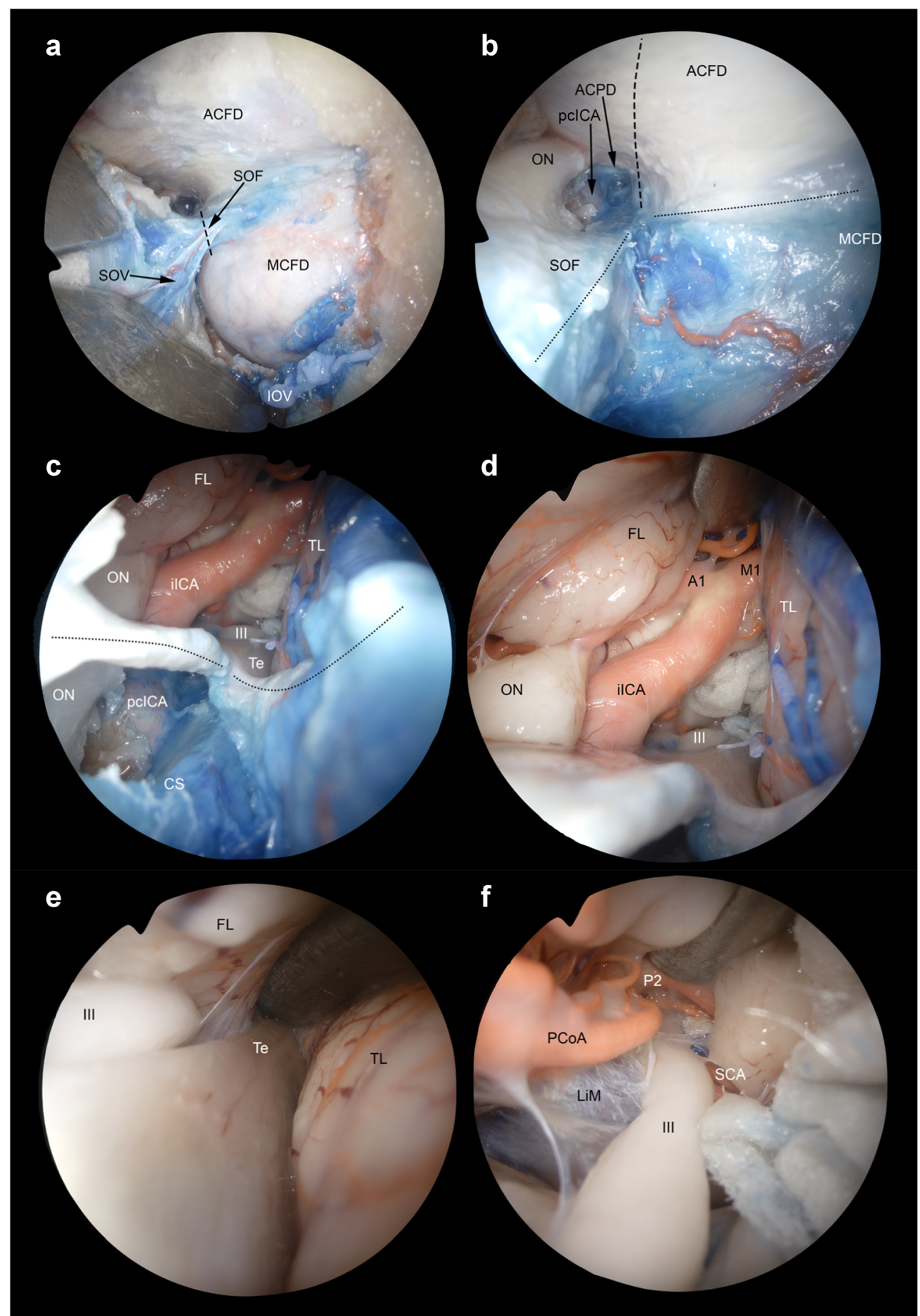

transnasal and/or open approaches. The authors however indicate that the TEA is a challenging route for the posterolateral triangle (corridor between the V3 and the petrous apex). They presented a case in which TEA was insufficient for approaching a dumbbell-shaped schwannoma involving the $\mathrm{MCF}$ and PCF who later required additional retrosigmoid surgery. Chen et al. [8] performed surgeries via TEA in two patients for lesions (gliosis) in the temporal lobe. They expressed that the TEA minimized risks related to conventional approaches to the temporal lobe like cognitive deficits, hemiparesis, cranial nerve deficits, and visual field loss by providing a direct path towards the temporal lobe and 
Fig. 9 Extended transorbital transdural approach to the internal carotid artery bifurcation and adjacent structures. A The corridors through the dura of the anterior (ACFD) and middle cranial fossa (MCFD) can be merged by sectioning the meningo-orbital fold (black dashed line) in the lateral portion of the superior orbital fissure (SOF), which, as opposed to the medial portion, does not contain relevant neurovascular structures other than the superior ophthalmic vein (SOV) and meningo-orbital/-lacrimal or recurrent meningeal branch of the middle meningeal artery. B After sectioning the meningo-orbital fold (black dotted line), the full exposure of the dura of the posterolateral anterior cranial fossa, parasellar area, and lateral middle cranial fossa is achieved. Anterior clinoid process dura (ACPD), optic nerve $(\mathrm{ON})$ and the paraclinoid tract of the internal carotid artery (pcICA) are identified. Among other potential transdural targets, the intracranial tract of the internal carotid artery (iICA) and its bifurcation can be exposed by incising the anterior cranial fossa and anterior clinoid process dura (black dashed line). This maneuver would be more difficult if the meningo-orbital fold is not sectioned. C Once the dura of the anterior clinoid process is incised, the following structures are encountered: oculomotor nerve (III), frontal lobe (FL), intracranial tract of the internal carotid artery, optic nerve, tentorium cerebri (Te), and temporal lobe (TL). Thanks to its tangential trajectory as respect to the anterior cranial fossa dural plane, the transorbital perspective provides the exposure of both the intradural and extradural portion of several neurovascular structures. Particularly, the figure shows both the intracranial and paraclinoid tract of the internal carotid artery as well as intradural and intracanalicular portions of the optic nerve. D The bifurcation of the internal carotid artery into the precommunicating tract of the anterior cerebral artery (A1) and proximal tract of the middle cerebral artery (M1) can be identified by moving the scope forward through the transdural window. E, F The free edge of the tentorium cerebri can be used as landmark to follow the oculomotor nerve (III) towards the ambiens cistern and interpeduncular fossa. The Liliequist's membrane (LiM), postcommunicating tract of the posterior cerebral artery (P2), posterior communicating artery $(\mathrm{PCoA})$, and superior cerebellar artery (SCA) can be also identified. CS, cavernous sinus; IOF, inferior ophthalmic vein

allowing earlier visualization of the target. It is also mentioned that by the TEA, the surgeon achieves an early visualization of the cranial nerves which may facilitate the avoidance of an injury. Studies indicate that the TEAs provided optimal exposure and surgical freedom for adequate handling of lesions of the $\mathrm{ACF}$ and $\mathrm{MCF}$ $[3,16,47]$. If needed, removal of the superior orbital wall is possible, exposing the entire ACF from the midline to its most lateral point. Suchlike, the removal of the lateral orbital wall may help for an adequate view of $\mathrm{MCF}$, from the lateral wall of the cavernous sinus to the lateral aspect of the temporal lobe [51].

TEAs have been successfully applied in various pathologies ranging from CSF leak to SB tumors (Table 6) $[3,8,12,16,27,28,32,36,40,43,47$, 53, 58]. Among tumors, with $67(65.6 \%)$ presented cases, meningioma was the most common pathology followed by trigeminal schwannomas $(9.8 \%)$. In the 102 tumor cases presented, $50(49.0 \%)$ gross-total resections, $9(8.8 \%)$ near-total resections, 30 (29.4\%) sub- total resections, and $6(5.9 \%)$ partial-resections were reported $[12,15,16,27,29,31,32,34,53,58]$. In 7 $(6.9 \%)$ patients, biopsies were obtained through TEAs $[27,28]$. Radiation therapy was performed with different techniques (stereotactic radiotherapy, Gamma Knife radiosurgery, proton beam radiotherapy) in 19 cases in whom noncomplete resection was achieved $[28,31$, 34]. Inflammatory pathologies like epidural abscesses, frontoorbital mucoceles, and cavernous sinus thrombosis were also managed by TEAs either alone or in combination with transnasal approach $[3,28,36,47]$.

With either small or invisible incisions, TEAs provide a pleasant cosmetic outcome. However, the absence of a surgical scar may give a misperception that the procedure is a minor surgery. The complications related to the globe, as well as neurovascular structures and eyelid apparatus, should always be kept in mind and the risks should be counseled with the patient (Tables 3 and 4). Care must be taken to protect the cornea and the globe intraoperatively as continuous orbital retraction may cause an increase of orbital pressure. This may also result in cardiac arrhythmias, thus, frequent monitoring of pupil size and blood pressure, along with electrocardiography, is required [29]. Intermittent relaxation of the eyeball every $20-30$ min during the procedure and keeping tissues dislocation less than $10 \mathrm{~mm}$ is recommended $[5,48,51]$.

Overall, TEAs have relatively less morbidity than traditional SB procedures. The reports indicate mostly minor morbidities, rapid postoperative healing, minimal pain, and short time of hospitalization [26, 39, 46, 47]. Despite these relatively low morbidity rates, it is the authors' opinion that it is still too emphatic to name them as minimal invasive approaches, as complications do occur in a non-negligible rate of patients $(31.1 \%)[3,14,34]$. Indeed, the classification employed in this systematic review rates complications such as diplopia and upper eyelid necrosis as minor events, whereas one should take into consideration the dismal impact of these occurrences on patient's quality of life. In fact, morbidity should not be considered as a secondary issue, as most patients receiving a TEA are affected by benign disease with good tumor-related prognosis and long-life expectancy.

The findings of the current study, aiming to summarize the surgical anatomy and objective clinical data on TEAs through a systematic review of the current literature, have to be seen in light of some limitations. Although it shows the anatomical approaches in detail with dissections, it does not include a quantitative analysis and comparison of each approach. The literature contains clinical studies with heterogenity both in terms of pathologies and approaches as well as patient numbers due to the relatively new growing nature of these approaches which makes the generalization of the findings difficult. 
Table 3 Complications of transorbital approaches in which surgical procedures were presented (numbers of complications) (superscripts in the first row indicate the reference numbers)

\begin{tabular}{lll}
\hline Author & Number of TO cases & Complications \\
\hline Jeon [29] & 9 & Complete ptosis improved in 6 months (1), mild ptosis (3) \\
De Rosa [16] & 1 & Proptosis which resolved in 6 months (1) \\
Lee [34] & 9 & Decrease in visual acuity (1), CN V neuropathy (2), CN VI neuropathy (2), ptosis (3) keratitis (2) \\
Golbin [28] & 12 & Transient CNV 1 hypoesthesia (2), transient ptosis (1) \\
Kong [31] & 18 & CSF leaks (2), transient lateral rectus muscle paresis (2), transient ptosis (3) \\
Dallan [15] & 14 & Upper eyelid necrosis (1), diplopia (3), CNV hypoesthesia (3), CNV $_{1}$ \\
& & hypoesthesia (1), palpebral edema (3) (of which 1 persistent) \\
Chen [8] & 2 & Orbital pseudomeningocele (1) \\
Dallan [12] & 4 & Superior eyelid edema (2) \\
Balakrishnan [3] & 107 & Diplopia (14), persistent vision change (3) \\
Park [53] & 11 & CSF leak (1), diplopia (1), ptosis (1) \\
Raza [58] & 6 & Diplopia (1) \\
Total Number & 193 & 60 (31.1\%) \\
\hline
\end{tabular}

Table 4 Rates of complications. * The rate of CSF leak in patients undergoing dural defect reconstruction is $4.1 \%$ (superscripts in the second row indicate the reference numbers)

\begin{tabular}{lllll}
\hline Complication & Number of cases & Single-series rate & $\begin{array}{l}\text { Overall rate in } \\
\text { complications }\end{array}$ & $\begin{array}{l}\text { Overall rate in } \\
\text { total cases }\end{array}$ \\
\hline Diplopia & $23[3,15,31,53,58]$ & $9.1-22.2 \%$ & $38.3 \%$ & $11.9 \%$ \\
Ptosis & $12[28,29,31,34,53]$ & $8.3-33.3 \%$ & $20 \%$ & $6.2 \%$ \\
Proptosis & $1[16]$ & $100 \%$ & $1.6 \%$ & $0.5 \%$ \\
Palpebral edema & $5[12,15]$ & $21.4-50 \%$ & $8.3 \%$ & $2.5 \%$ \\
CSF Leak & $3[31,53]$ & $9-11.1 \%$ & $5 \%$ & $1.5 \% *$ \\
Vision change & $4[3,34]$ & $2.8-11.1 \%$ & $6.6 \%$ & $2 \%$ \\
Orbital pseudomeningocele & $1[8]$ & $50 \%$ & $1.6 \%$ & $0.5 \%$ \\
Keratitis & $2[34]$ & $22.2 \%$ & $3.3 \%$ & $1 \%$ \\
Trigeminal nerve neuropathy & $8[15,28,34]$ & $16.6-28.5 \%$ & $13.3 \%$ & $4.1 \%$ \\
Upper eyelid necrosis & $1[15]$ & $7.1 \%$ & $1.6 \%$ & $0.5 \%$ \\
\hline
\end{tabular}

Table 5 The Clavien-Dindo Classification of Surgical Complications [56]

\begin{tabular}{|c|c|}
\hline Grade & Description \\
\hline Grade 1 & $\begin{array}{l}\text { Any deviation from the normal postoperative course not requiring surgical, endoscopic or radiological } \\
\text { intervention. (Allowed therapeutic regimens are: drugs as antiemetics, antipyretics, analgesics, diuretics, } \\
\text { electrolytes, and physiotherapy. This grade also includes wound infections opened at the bedside) }\end{array}$ \\
\hline Grade 2 & $\begin{array}{l}\text { Requiring pharmacological treatment with drugs other than such allowed for grade I complications Blood } \\
\text { transfusions and total parenteral nutrition are also included }\end{array}$ \\
\hline Grade 3 & $\begin{array}{l}\text { Complications requiring surgical, endoscopic or radiological intervention } \\
\text { Grade } 3 \mathrm{a} \text {-intervention not under general anesthetic } \\
\text { Grade } 3 \mathrm{~b} \text {-intervention under general anesthetic }\end{array}$ \\
\hline Grade 4 & $\begin{array}{l}\text { Life-threatening complications; this includes central nervous system complications which require } \\
\text { intensive care } \\
\text { Grade } 4 \mathrm{a} \text { - single-organ dysfunction (including dialysis) } \\
\text { Grade } 4 \mathrm{~b} \text { - multi-organ dysfunction }\end{array}$ \\
\hline Grade 5 & Death of the patient \\
\hline
\end{tabular}


Table 6 Pathologies and clinical conditions for which transorbital endoscopic surgeries were applied in the literature

\begin{tabular}{lll}
\hline Pathologies and clinical conditions & Number of cases & References \\
\hline Meningioma & $67(45.0 \%)$ & {$[12,15,16,28,29,31,32,34,40,53]$} \\
Schwannoma & $10(6.7 \%)$ & {$[12,29,31,34]$} \\
Dermoid cyst & $2(1.3 \%)$ & {$[29,34]$} \\
Chondrosarcoma & $2(1.3 \%)$ & {$[29,34]$} \\
Osteoblastoma & $1(0.7 \%)$ & {$[28]$} \\
Osteosarcoma & $1(0.7 \%)$ & {$[31]$} \\
Gliosis & $2(1.3 \%)$ & {$[8]$} \\
Inflammation/infection/abscess & $17(11.4 \%)$ & {$[3,36,47]$} \\
CSF Leak & $23(15.4 \%)$ & {$[3,41,47,48,58]$} \\
Plasmocytoma & $1(0.7 \%)$ & {$[31]$} \\
Teratoma & $1(0.7 \%)$ & {$[31]$} \\
Glioblastoma & $1(0.7 \%)$ & {$[27]$} \\
Metastatic tumor & $2(1.3 \%)$ & {$[28,29]$} \\
Mucocele & $7(4.7 \%)$ & {$[26,36,47]$} \\
Hemangioma & $1(0.7 \%)$ & {$[43]$} \\
Cavernous sinus thrombosis & $1(0.7 \%)$ & {$[36]$} \\
Sebaceus gland carcinoma & $1(0.7 \%)$ & {$[31]$} \\
Malignant peripheral nerve sheat tumor & $1(0.7 \%)$ & {$[28]$} \\
Pituitary adenoma & $1(0.7 \%)$ & {$[32]$} \\
Adenoid cystic carcinoma & $1(0.7 \%)$ & {$[47]$} \\
Juvenile nasopharyngeal angiofibroma & $1(0.7 \%)$ & {$[58]$} \\
Olfactory neuroblastoma & $1(0.7 \%)$ & {$[58]$} \\
Paget disease & $1(0.7 \%)$ & {$[58]$} \\
Pseudotumor & $3(0.7 \%)$ & \\
TOTAL & 149 & \\
\hline & & \\
\hline
\end{tabular}

\section{Conclusion}

This study aimed to display each method of transorbital endoscopic surgery with anatomical dissections and to condense the data regarding this subject by making a systematic review of the current literature. It would be precise to comment that TEAs are important bricks in the wall of the endoscopic approaches to the SB. Data clustered so far indicate that these approaches provide important advantages reaching different pathologies and target areas through the SB. These versatile approaches allow the surgeon to avoid extra soft tissue dissection and provide a relatively short and direct corridor. They are not proposed to replace the transnasal or external approaches but are useful and important complementaries that should be in the armamentarium of a SB team.

Supplementary Information The online version contains supplementary material available at https://doi.org/10.1007/s10143-020-01470-5.

Acknowledgments Olympus Europa SE \& Co. KG is acknowledged for supporting the present study through provision of $4 \mathrm{~K}$ endoscopic camera and endoscopes. The Center for Anatomy and Cell Biology (Division of Anatomy) of the Medical University of Vienna is acknowledged for providing the laboratory and instrumentation for anatomical dissection. The
Authors acknowledge MedCure's provision of anatomical specimens. The references 22, 34 and 60 were published online during the peerreview process and are therefore not included in the systematic review.

Authors' contributions AV, MF, VR, AS and FD: Design of the study; AV, ALCC, MF, VR, DM, AS, FD, BB, ST, MT and TG: Cadaver dissections, collecting of data; AV, ALCC: Literature review; AD, LH, PN: Supervision of the project; AV, ALCC, MF, VR: Writing the study with input from all authors; MF, VR, TG, ST, MT: Praparation of figures; MF, FD, AS, DM, LFR, AD, LH, PN: Final editing of the study; All authors provided critical feedback and helped shape the manuscript. The authors confirm that they have reviewed and approved the manuscript.

Funding Open Access funding provided by Università degli Studi di Brescia.

Data availability Not applicable.

\section{Compliance with ethical standards}

Conflict of interest The authors declare that they have no conflict of interest.

Ethical approval Approval for the study by the local ethics commission was obtained (EC Nr. 1277/2016) 
Consent to participate Not applicable.

Consent for publication Not applicable.

Code availability Not applicable.

Open Access This article is licensed under a Creative Commons Attribution 4.0 International License, which permits use, sharing, adaptation, distribution and reproduction in any medium or format, as long as you give appropriate credit to the original author(s) and the source, provide a link to the Creative Commons licence, and indicate if changes were made. The images or other third party material in this article are included in the article's Creative Commons licence, unless indicated otherwise in a credit line to the material. If material is not included in the article's Creative Commons licence and your intended use is not permitted by statutory regulation or exceeds the permitted use, you will need to obtain permission directly from the copyright holder. To view a copy of this licence, visit http://creativecommons.org/licenses/by/4.0/.

\section{References}

1. Almeida JP, Ruiz-Trevino AS, Shetty SR, Omay SB, Anand VK, Schwartz TH (2017) Transorbital endoscopic approach for exposure of the sylvian fissure, middle cerebral artery and crural cistern: an anatomical study. Acta Neurochir 159:1893-1907. https://doi. org/10.1007/s00701-017-3296-8

2. Alqahtani A, Padoan G, Segnini G, Lepera D, Fortunato S, Dallan I, Pistochini A, Abdulrahman S, Abbate V, Hirt B, Castelnuovo P (2015) Transorbital transnasal endoscopic combined approach to the anterior and middle skull base: a laboratory investigation. Acta Otorhinolaryngol Ital 35:173-179

3. Balakrishnan K, Moe KS (2011) Applications and outcomes of orbital and transorbital endoscopic surgery. Otolaryngol Head Neck Surg 144:815-820. https://doi.org/10.1177/ 0194599810397285

4. Bly RA, Su D, Hannaford B, Ferreira M Jr, Moe KS (2012) Computer modeled multiportal approaches to the skull base. J Neurol Surg B Skull Base 73:415-423. https://doi.org/10.1055/s0032-1329623

5. Bly RA, Ramakrishna R, Ferreira M, Moe KS (2014) Lateral transorbital neuroendoscopic approach to the lateral cavernous sinus. J Neurol Surg B Skull Base 75:11-17. https://doi.org/10.1055/ s-0033-1353363

6. Bly RA, Ramakrishna R, Ferreira M, Moe KS (2014) Lateral transorbital neuroendoscopic approach to the lateral cavernous sinus. Journal of Neurological Surgery Part B. Skull Base 75:011017

7. Cavallo LM, Somma T, Solari D, Iannuzzo G, Frio F, Baiano C, Cappabianca P (2019) Endoscopic endonasal transsphenoidal surgery: history and evolution. World Neurosurg 127:686-694. https://doi.org/10.1016/j.wneu.2019.03.048

8. Chen HI, Bohman LE, Emery L, Martinez-Lage M, Richardson AG, Davis KA, Pollard JR, Litt B, Gausas RE, Lucas TH (2015) Lateral transorbital endoscopic access to the hippocampus, amygdala, and entorhinal cortex: initial clinical experience. ORL J Otorhinolaryngol Relat Spec 77:321-332. https://doi.org/10.1159/ 000438762

9. Ciporen JN, Moe KS, Ramanathan D, Lopez S, Ledesma E, Rostomily R, Sekhar LN (2010) Multiportal endoscopic approaches to the central skull base: a cadaveric study. World Neurosurg 73:705-712. https://doi.org/10.1016/j.wneu.2010.03. 033
10. Ciporen J, Lucke-Wold B, Dogan A, Cetas JS, Cameron WE (2016) Dual endoscopic endonasal transsphenoidal and precaruncular transorbital approaches for clipping of the cavernous carotid artery: a cadaveric simulation. J Neurol Surg B Skull Base 77:485-490. https://doi.org/10.1055/s-0036-1584094

11. Ciporen JN, Lucke-Wold B, Dogan A, Cetas J, Cameron W (2017) Endoscopic endonasal transclival approach versus dual transorbital port technique for clip application to the posterior circulation: a cadaveric anatomical and cerebral circulation simulation study. J Neurol Surg B Skull Base 78:235-244. https://doi.org/10.1055/s0036-1597278

12. Dallan I, Castelnuovo P, Locatelli D, Turri-Zanoni M, AlQahtani A, Battaglia P, Hirt B, Sellari-Franceschini S (2015) Multiportal combined transorbital transnasal endoscopic approach for the management of selected skull base lesions: preliminary experience. World Neurosurg 84:97-107. https://doi.org/10.1016/j.wneu. 2015.02.034

13. Dallan I, Locatelli D, Turri-Zanoni M, Battaglia P, Lepera D, Galante N, Sellari-Franceschini S, Castelnuovo P (2015) Transorbital endoscopic assisted resection of a superior orbital fissure cavernous haemangioma: a technical case report. Eur Arch Otorhinolaryngol 272:3851-3856. https://doi.org/10.1007/ s00405-015-3556-2

14. Dallan I, Di Somma A, Prats-Galino A, Solari D, Alobid I, TurriZanoni M, Fiacchini G, Castelnuovo P, Catapano G, de Notaris M (2017) Endoscopic transorbital route to the cavernous sinus through the meningo-orbital band: a descriptive anatomical study. $\mathrm{J}$ Neurosurg 127:622-629. https://doi.org/10.3171/2016.8. JNS16465

15. Dallan I, Sellari-Franceschini S, Turri-Zanoni M, de Notaris M, Fiacchini G, Fiorini FR, Battaglia P, Locatelli D, Castelnuovo P (2018) Endoscopic transorbital superior eyelid approach for the management of selected spheno-orbital meningiomas: preliminary experience. Oper Neurosurg (Hagerstown) 14:243-251. https://doi. org/10.1093/ons/opx 100

16. De Rosa A, Pineda J, Cavallo LM, Di Somma A, Romano A, Topczewski TE, Somma T, Solari D, Ensenat J, Cappabianca P, Prats-Galino A (2019) Endoscopic endo- and extra-orbital corridors for spheno-orbital region: anatomic study with illustrative case. Acta Neurochir 161:1633-1646. https://doi.org/10.1007/s00701019-03939-9

17. Di Ieva A (2016) Lee JM. Handbook of skull base surgery. Thieme Medical Publishers, Cusimano MD

18. Di Somma A, Cavallo LM, de Notaris M, Solari D, Topczewski TE, Bernal-Sprekelsen M, Ensenat J, Prats-Galino A, Cappabianca P (2017) Endoscopic endonasal medial-to-lateral and transorbital lateral-to-medial optic nerve decompression: an anatomical study with surgical implications. J Neurosurg 127:199-208. https://doi. org/10.3171/2016.8.JNS16566

19. Di Somma A, Andaluz N, Cavallo LM, de Notaris M, Dallan I, Solari D, Zimmer LA, Keller JT, Zuccarello M, Prats-Galino A, Cappabianca P (2018) Endoscopic transorbital superior eyelid approach: anatomical study from a neurosurgical perspective. J Neurosurg 129:1203-1216. https://doi.org/10.3171/2017.4. JNS162749

20. Di Somma A, Andaluz N, Cavallo LM, Keller JT, Solari D, Zimmer LA, de Notaris M, Zuccarello M, Cappabianca P (2018) Supraorbital vs endo-orbital routes to the lateral skull base: a quantitative and qualitative anatomic study. Oper Neurosurg (Hagerstown) 15:567-576. https://doi.org/10.1093/ons/opx256

21. Di Somma A, Andaluz N, Cavallo LM, Topczewski TE, Frio F, Gerardi RM, Pineda J, Solari D, Ensenat J, Prats-Galino A, Cappabianca P (2018) Endoscopic transorbital route to the petrous apex: a feasibility anatomic study. Acta Neurochir 160:707-720. https://doi.org/10.1007/s00701-017-3448-x 
22. Di Somma A, Langdon C, de Notaris M, Reyes L, Ortiz-Perez S, Alobid I, Ensenat J (2020) Combined and simultaneous endoscopic endonasal and transorbital surgery for a Meckel's cave schwannoma: technical nuances of a mini-invasive, multiportal approach. J Neurosurg:1-10. https://doi.org/10.3171/2020.4. JNS20707

23. Dindo D, Demartines N, Clavien PA (2004) Classification of surgical complications: a new proposal with evaluation in a cohort of 6336 patients and results of a survey. Ann Surg 240:205-213. https://doi.org/10.1097/01.sla.0000133083.54934.ae

24. Duz B, Secer HI, Gonul E (2009) Endoscopic approaches to the orbit: a cadaveric study. Minim Invasive Neurosurg 52:107-113. https://doi.org/10.1055/s-0029-1220931

25. Ferrari M, Schreiber A, Mattavelli D, Belotti F, Rampinelli V, Lancini D, Doglietto F, Fontanella MM, Tschabitscher M, Rodella LF, Nicolai P (2016) The inferolateral transorbital endoscopic approach: a preclinical anatomic study. World Neurosurg 90:403-413. https://doi.org/10.1016/j.wneu.2016.03.017

26. Gassner HG, Schwan F, Schebesch KM (2015) Minimally invasive surgery of the anterior skull base: transorbital approaches. GMS Curr Top Otorhinolaryngol Head Neck Surg 14:Doc03. In: doi: $10.3205 /$ cto000118

27. Gerges MM, Godil SS, Younus I, Rezk M, Schwartz TH (2019) Endoscopic transorbital approach to the infratemporal fossa and parapharyngeal space: a cadaveric study. J Neurosurg 1:1-12

28. Golbin DA, Lasunin NV, Cherekaev VA, Grigorieva NN, Serova NK, Mindlin SN, Kutin MA, Imaev AA (2019) Biopsy and resection of skull base tumors using transorbital endoscopic approaches: primary results. Zh Vopr Neirokhir Im N N Burdenko 83:42-56. https://doi.org/10.17116/neiro20198303142

29. Jeon C, Hong CK, Woo KI, Hong SD, Nam DH, Lee JI, Choi JW, Seol HJ, Kong DS (2018) Endoscopic transorbital surgery for Meckel's cave and middle cranial fossa tumors: surgical technique and early results. J Neurosurg:1-10. https://doi.org/10.3171/2018. 6.JNS181099

30. Kasemsiri P, Carrau RL, Ditzel Filho LF, Prevedello DM, Otto BA, Old M, de Lara D, Kassam AB (2014) Advantages and limitations of endoscopic endonasal approaches to the skull base. World Neurosurg 82:S12-S21. https://doi.org/10.1016/j.wneu.2014.07. 022

31. Kong DS, Young SM, Hong CK, Kim YD, Hong SD, Choi JW, Seol HJ, Lee JI, Shin HJ, Nam DH, Woo KI (2018) Clinical and ophthalmological outcome of endoscopic transorbital surgery for cranioorbital tumors. J Neurosurg 131:667-675. https://doi.org/ 10.3171/2018.3.JNS173233

32. Koppe M, Gleizal A, Orset E, Bachelet JT, Jouanneau E, Rougeot A (2013) Superior eyelid crease approach for transobital neuroendoscopic surgery of the anterior cranial fossa. J Craniofac Surg 24:1616-1621. https://doi.org/10.1097/SCS. 0b013e3182a2d635

33. Laleva L, Spiriev T, Dallan I, Prats-Galino A, Catapano G, Nakov V, de Notaris M (2019) Pure endoscopic lateral orbitotomy approach to the cavernous sinus, posterior, and infratemporal fossae: anatomic study. J Neurol Surg B Skull Base 80:295-305. https:// doi.org/10.1055/s-0038-1669937

34. Lee MH, Hong SD, Woo KI, Kim YD, Choi JW, Seol HJ, Lee JI, Shin HJ, Nam DH, Kong DS (2019) Endoscopic endonasal versus transorbital surgery for middle cranial fossa tumors: comparison of clinical outcomes based on surgical corridors. World Neurosurg 122:e1491-e1504. https://doi.org/10.1016/j.wneu.2018.11.090

35. Li L, London NR Jr, Chen X, Prevedello DM, Carrau RL (2020) Expanded exposure and detailed anatomic analysis of the superior orbital fissure: implications for endonasal and transorbital approaches. Head Neck 42:3089-3097. https://doi.org/10.1002/hed. 26399
36. Lim JH, Sardesai MG, Ferreira M Jr, Moe KS (2012) Transorbital neuroendoscopic management of sinogenic complications involving the frontal sinus, orbit, and anterior cranial fossa. J Neurol Surg B Skull Base 73:394 400. https://doi.org/10.1055/s-0032-1329617

37. Lin BJ, Hong KT, Chung TT, Liu WH, Hueng DY, Chen YH, Ju DT, Ma HI, Liu MY, Hung HC, Tang CT (2019) Endoscopic transorbital transtentorial approach to middle incisural space: preclinical cadaveric study. Acta Neurochir 161:831-839. https://doi. org/10.1007/s00701-019-03831-6

38. Lin BJ, Ju DT, Hsu TH, Chung TT, Liu WH, Hueng DY, Chen YH, Hsia CC, Ma HI, Liu MY, Hung HC, Tang CT (2019) Endoscopic transorbital approach to anterolateral skull base through inferior orbital fissure: a cadaveric study. Acta Neurochir 161:1919-1929. https://doi.org/10.1007/s00701-019-03993-3

39. Locatelli D, Pozzi F, Turri-Zanoni M, Battaglia P, Santi L, Dallan I, Castelnuovo P (2016) Transorbital endoscopic approaches to the skull base: current concepts and future perspectives. J Neurosurg Sci 60:514-525

40. Lubbe D, Mustak H, Taylor A, Fagan J (2017) Minimally invasive endo-orbital approach to sphenoid wing meningiomas improves visual outcomes - our experience with the first seven cases. Clin Otolaryngol 42:876-880. doi:https://doi.org/10.1111/coa.12722

41. Lubbe DE, Douglas-Jones P, Wasl H, Mustak H, Semple PL (2020) Contralateral precaruncular approach to the lateral sphenoid sinus-a case report detailing a new, multiportal approach to lesions, and defects in the lateral aspect of well-pneumatized sphenoid sinuses. Ear Nose Throat J 99:62-67. https://doi.org/10.1177/ 0145561319846828

42. Lund VJ, Stammberger H, Nicolai P, Castelnuovo P, Beal T, Beham A, Bernal-Sprekelsen M, Braun H, Cappabianca P, Carrau R, Cavallo L, Clarici G, Draf W, Esposito F, Fernandez-Miranda J, Fokkens W, Gardner P, Gellner V, Hellquist H, Hermann P, Hosemann W, Howard D, Jones N, Jorissen M, Kassam A, Kelly D, Kurschel-Lackner S, Leong S, McLaughlin N, Maroldi R, Minovi A, Mokry M, Onerci M, Ong YK, Prevedello D, Saleh H, Sehti DS, Simmen D, Snyderman C, Solares A, Spittle M, Stamm A, Tomazic P, Trimarchi M, Unger F, Wormald PJ, Zanation A, European Rhinologic Society Advisory Board on Endoscopic Techniques in the Management of Nose PS, Skull Base T (2010) European position paper on endoscopic management of tumours of the nose, paranasal sinuses and skull base. Rhinol Suppl 22:1-143

43. Lyson T, Sieskiewicz A, Rogowski M, Mariak Z (2014) Endoscopic lateral orbitotomy. Acta Neurochir 156:1897-1900. https://doi.org/10.1007/s00701-014-2205-7

44. Matsuo S, Komune N, Iihara K, Rhoton AL Jr (2016) Translateral orbital wall approach to the orbit and cavernous sinus: anatomic study. Oper Neurosurg (Hagerstown) 12:360-373. https://doi.org/ 10.1227/NEU.0000000000001145

45. Meccariello G, Deganello A, Choussy O, Gallo O, Vitali D, De Raucourt D, Georgalas C (2016) Endoscopic nasal versus open approach for the management of sinonasal adenocarcinoma: a pooled-analysis of 1826 patients. Head Neck 38(Suppl 1):E2267E2274. https://doi.org/10.1002/hed.24182

46. Moe KS (2014) Transorbital endoscopic approaches to the anterior cranial fossa. In: Gardner P. In: Synerderman Carl H (ed) Master techniques in otolaryngology-head and neck surgery: skull base surgery 1st Edition

47. Moe KS, Bergeron CM, Ellenbogen RG (2010) Transorbital neuroendoscopic surgery. Neurosurgery 67:ons16-ons 28 . https:// doi.org/10.1227/01.NEU.0000373431.08464.43

48. Moe KS, Kim LJ, Bergeron CM (2011) Transorbital endoscopic repair of cerebrospinal fluid leaks. Laryngoscope 121:13-30. https://doi.org/10.1002/lary.21280

49. Nicolai P, Ferrari M, Maroldi R (2019) Endoscopic transnasal anatomy of the skull base and adjacent areas: a lab dissection and radiological atlas. Thieme 
50. Noiphithak R, Yanez-Siller JC, Revuelta Barbero JM, Otto BA, Carrau RL, Prevedello DM (2018) Quantitative analysis of the surgical exposure and surgical freedom between transcranial and transorbital endoscopic anterior petrosectomies to the posterior fossa. J Neurosurg 131:569-577. https://doi.org/10.3171/2018.2. JNS172334

51. Noiphithak R, Yanez-Siller JC, Revuelta Barbero JM, Cho RI, Otto BA, Carrau RL, Prevedello DM (2019) Comparative analysis of the exposure and surgical freedom of the endoscopic extended minipterional craniotomy and the transorbital endoscopic approach to the anterior and middle cranial fossae. Oper Neurosurg (Hagerstown) 17:174-181. https://doi.org/10.1093/ons/opy309

52. Noiphithak R, Yanez-Siller JC, Revuelta Barbero JM, Otto BA, Carrau RL, Prevedello DM (2019) Comparative analysis between lateral orbital rim preservation and osteotomy for transorbital endoscopic approaches to the cavernous sinus: an anatomic study. Oper Neurosurg (Hagerstown) 16:86-93. https://doi.org/10.1093/ons/ opy054

53. Park HH, Yoo J, Yun IS, Hong CK (2020) Comparative analysis of endoscopic transorbital approach and extended mini-pterional approach for sphenoid wing meningiomas with osseous involvement: preliminary surgical results. World Neurosurg. https://doi.org/10. 1016/j.wneu.2020.01.115

54. Patel CR, Fernandez-Miranda JC, Wang WH, Wang EW (2016) Skull base anatomy. Otolaryngol Clin N Am 49:9-20. https://doi. org/10.1016/j.otc.2015.09.001

55. Prabhakaran VC, Selva D (2008) Orbital endoscopic surgery. Indian J Ophthalmol 56:5-8. https://doi.org/10.4103/0301-4738. 37587

56. Priddy BH, Nunes CF, Beer-Furlan A, Carrau R, Dallan I, Prevedello DM (2017) A side door to Meckel's cave: anatomic feasibility study for the lateral transorbital approach. Oper Neurosurg (Hagerstown) 13:614-621. https://doi.org/10.1093/ ons/opx042

57. Ramakrishna R, Kim LJ, Bly RA, Moe K, Ferreira M Jr (2016) Transorbital neuroendoscopic surgery for the treatment of skull base lesions. J Clin Neurosci 24:99-104. https://doi.org/10.1016/j. jocn.2015.07.021

58. Raza SM, Quinones-Hinojosa A, Lim M, Boahene KD (2013) The transconjunctival transorbital approach: a keyhole approach to the midline anterior skull base. World Neurosurg 80:864-871. https:// doi.org/10.1016/j.wneu.2012.06.027

59. Saraceno G, Agosti E, Qiu J, Buffoli B, Ferrari M, Raffetti E, Belotti F, Ravanelli M, Mattavelli D, Schreiber A, Hirtler L, Rodella LF, Maroldi R, Nicolai P, Gentili F, Kucharczyk W, Fontanella MM, Doglietto F (2020) Quantitative anatomical comparison of anterior, anterolateral and lateral, microsurgical and endoscopic approaches to the middle cranial fossa. World Neurosurg 134:e682-e730. https://doi.org/10.1016/j.wneu.2019.10.178

60. Snyderman C, Gardner P (2014) Master techniques in otolaryngology-head and neck surgery: skull base surgery. Lippincott Williams \& Wilkins

61. Topczewski TE, Di Somma A, Pineda J, Ferres A, Torales J, Reyes L, Morillas R, Solari D, Cavallo LM, Cappabianca P, Ensenat J, Prats-Galino A (2020) Endoscopic endonasal and transorbital routes to the petrous apex: anatomic comparative study of two pathways. Acta Neurochir 162:2097-2109. https://doi.org/10. 1007/s00701-020-04451-1

62. Verillaud B, Bresson D, Sauvaget E, Mandonnet E, Georges B, Kania R, Herman P (2012) Endoscopic endonasal skull base surgery. Eur Ann Otorhinolaryngol Head Neck Dis 129:190-196. https://doi.org/10.1016/j.anorl.2011.09.004

63. Zwagerman NT, Zenonos G, Lieber S, Wang WH, Wang EW, Fernandez-Miranda JC, Snyderman CH, Gardner PA (2016) Endoscopic transnasal skull base surgery: pushing the boundaries. J Neuro-Oncol 130:319-330. https://doi.org/10.1007/s11060-0162274-y

Publisher's note Springer Nature remains neutral with regard to jurisdictional claims in published maps and institutional affiliations. 